\title{
UNA VISIÓN DE XOCHICALCO EN EL SIGLO XIX: DUPAIX Y CASTAÑEDA, 1805
}

AUGUSTO MOLINA MONTES

A Roberto Moreno de los Arcos

Los escritos de los autores-viajeros tanto mexicanos como extranjeros, que recorrieron el territorio de México en el siglo XIX, constituyen una valiosa fuente de información acerca de costumbres, paisajes urbanos y rurales, economía y sistemas de producción, transportes y otros aspectos de la historia cultural y política de México en esa época. Son especialmente importantes para la historia de la arqueología y de los monumentos prehispánicos, muchos de los cuales fueron descubiertos y dados a conocer por esos viajeros, quienes las más de las veces eran, además, audaces exploradores, arqueólogos aficionados o buscadores de tesoros, y viajaron cuando los transportes y las vías de comunicación eran primitivos o inexistentes y cuando no contaban con las comodidades y conveniencia de American Express, Visa o Carnet. Basta leer algunos pasajes de las andanzas de Stephens y Catherwood por tierras mayas a mediados del siglo para reconocer las dificultades y peligros de tales viajes.

Las motivaciones de estos personajes eran muchas y muy diversas. Mucho se ha insistido en que la mayoría de los viajeros extranjeros principalmente perseguían fines puramente políticos y económicos o se dedicaban al saqueo y coleccionismo de piezas arqueológicas. Pero, como acertadamente señala Fausto Ramírez, "tan falso... sería idealizar las intenciones de los viajeros como atribuir su interés al simple afán de lucro o a un objetivo puramente venal". ${ }^{1}$ Casi todos ellos tenían en común un especial interés en conocer países y regiones apartadas, entonces poco conocidas y consideradas "exóticas" y misteriosas por el romanticismo decimonónico del mundo occidental. Estos viajeros que recorrieron territorio mexicano en el siglo $\mathrm{xIX}$ reflejan la curiosidad de los humanos por conocer lo antiguo y lo distante. Continúan una larga tradición de libros y crónicas de viaje. Pausanias en el siglo II, y Marco Polo en el XIII, ya ejercitaban este género de la narrativa que tendría aún más aceptación hacia mediados del siglo

1 Fausto Ramírez, "La visión europea de la América Tropical: los artistas viajeros". Historia del Arte Mexicano, México, Salvat Mexicana de Ediciones, 1982, p. 149. 
XVIII con la publicación de las noticias del descubrimiento de Herculano y con los libros de viajes a Grecia y al Asia Menor, tales como The Antiquities of Athens de James Stuart y Nicholas Revett publicada en 1762 y considerada por algunos como el inicio de la arqueología científica. $^{2}$

Otro aspecto importante de los literatos-viajeros en México es su relevante papel en difundir una visión más real del país en el extranjero y provocar un renacimiento del interés por los monumentos y edificios y, en general, por las culturas del México prehispánico, fomentando así un sentido de identidad nacional entre los propios mexicanos.

No menos importantes para el conocimiento de la cultura mexicana son los grabados basados en los dibujos de los propios escritores y de los artistas que fueron comisionados para ilustrar estos relatos y quienes, en la mayoría de los casos, acompañaron a los autores en sus recorridos y pasaron las mismas penalidades. Tal es el caso de José Luciano Castañeda, el dibujante que acompañó a Guillermo Dupaix en tres expediciones realizadas entre 1805 y 1807.

Guillermo Dupaix fue uno de los primeros y más notables autores viajeros del siglo XIx en México. Nacido en 1750 en el Ducado de Luxemburgo que entonces era parte del imperio austro-húngaro, Dupaix desde joven se trasladó a España donde inició su carrera militar. Seguramente tuvo una adecuada formación humanista de tipo enciclopédico: tuvo, además, ocasión de viajar por Italia, Grecia y el norte de África y es probable que así se despertaran sus inquietudes de arqueólogo aficionado. Posteriormente, fue comisionado con el grado de capitán al Regimiento de Dragones de México, a donde llegó en 1791 y en donde permanecería hasta su muerte ocurrida en 1817 en la Ciudad de México.

En 1803, Carlos IV monarca ilustrado y como su padre interesado en la arqueología, ordenó se hiciera un reconocimiento de territorios de la Nueva España para explorar y conocer sitios y antigüedades, debiéndose "sacar diseños exactos de los edificios y demás monumentos antiguos que conduzcan a la inteligencia de la historia del país, no menos que a dar idea del gusto y perfección que los naturales consiguieron en las artes". ${ }^{3}$ Dupaix, quien para entonces se había retirado del 1952.

2 Cf. Glyn E., Daniel, A Hundred Years of Archaeology. Londres, G. Duckworth Co.,

${ }^{3}$ Roberto Villaseñor, Introducción a Guillermo Dupaix, Atlas de las Antigüedades Mexicanas, halladas en el Curso de Tres Viajes de la Real Expedición de Antigüedades de la Nueva España, emprendidas en 1805, 1806 y 1807. México, San Ángel, 1978, p. 30. 
ejército y ya era conocido en México como anticuario y coleccionista de piezas prehispánicas, fue seleccionado para dirigir este reconocimiento y, acompañado por el dibujante mexicano José Luciano Castaneda, un escribiente y dos soldados de caballería, realizó tres expediciones que recorrieron grandes distancias entre los años de 1805 a 1807.

La motivación de Dupaix para estos viajes fue distinta a la de otros viajeros de la época; él estaba cumpliendo con una misión oficial de exploración y registro. No fue el primero en recibir una comisión similar. Recordemos que la Real Audiencia de Guatemala desde 1784 había enviado varias expediciones para reconocer las ruinas de Palenque, entre otras la tristemente célebre comandada por el capitán Antonio del Río en 1787 y que tantos destrozos causó en el sitio. Sí fue Dupaix, sin embargo, el primero en recorrer grandes extensiones del territorio mexicano, desde los valles de México y Puebla hasta Oaxaca y Chiapas, primordialmente en búsqueda y registro oficial de antigüedades mexicanas. Demostró, además, sensibilidad hacia el objeto de su misión y reconoció la importancia que tienen las ruinas de edificios antiguos para mejor conocer a las civilizaciones que los produjeron. Refiriéndose a las ruinas de Monte Albán, escribió:

Esta escuela original antiquísima americana, estas fábricas y muchas otras esparcidas por el nuevo continente, nos demuestran de más a más, unos conocimientos que nunca se podrían sospechar de una nación que siempre ha sido reputada de bárbara, injustamente. ${ }^{4}$

Como resultado de sus viajes Dupaix y Castañeda, en el curso de sus tres expediciones visitaron, describieron e ilustraron numerosos sitios prehispánicos, entre otros Huatusco, Cholula, Xochicalco, Mitla, Monte Albán y Palenque.

José Luciano Castañeda, el dibujante seleccionado por Dupaix para acompañarlo en sus tres expediciones, nació en Toluca el año de 1774. Se sabe que estudió dibujo y pintura en la Academia de México y el mismo Dupaix lo describe como "pintor y delineador" $y$, en otra versión, como "pensionado de esta Real Academia y profesor de dibu-

4 Guillermo Dupaix, Expediciones acerca de los Antiguos Monumentos de la Nueva España 1805-1808. edic., intr. y notas de José Alcina Franch. Madrid, José Porrúa Turanzas, 1969, p. 116.

5 Guillermo Dupaix, op. cit., 1978, p. 59. 
jo y arquitectura". ${ }^{6}$ No se sabe con certeza la fecha de la muerte de Castañeda que debió ocurrir a fines de la década de los 1830 .

Muy diversas son las opiniones que se han expresado acerca de la calidad y fidelidad de las ilustraciones de Castañeda que aparecen en las publicaciones europeas de los viajes de Dupaix. Frecuentemente se ha señalado que para juzgarlas se debe tomar en cuenta que los grabadores europeos interpretaron y modificaron los dibujos originales "embelleciéndolos" y "corrigiéndolos" muy a su manera.

Fausto Ramírez señala que además de las modificaciones ocurridas en el traslado de los bocetos originales a la plancha grabada,

los primeros artistas viajeros (incluido Castañeda), formados dentro de los principios clásicos solían adolecer de una total incapacidad para mirar y reproducir con objetividad las intricadas formas prehispánicas... Las producciones precolombinas obedecían a un sistema de convenciones formales radicalmente distinto al aceptado en occidente; de ahí la dificultad no sólo para reproducirlas sino incluso para verlas con objetividad.?

Por otra parte, debe de haber sido difícil para Castañeda seguir el paso a Dupaix, hombre militar y entrenado en los rigores de recorridos y viajes. Aunque poco afecto a lo anecdótico, Dupaix nos dice que durante el primer viaje, estando en Huatusco, "me hizo patente el pin." tor que no podia seguir adelante, por falta de salud" ${ }^{8}$ En otros pasajes cuenta algunos accidentes y percances que sufrió Castañeda. Es casi seguro que durante el viaje, debido a la premura del tiempo, el estado ruinoso de las construcciones y objetos arqueológicos, y a las dificultades del dibujo en el campo, el dibujante tomó apuntes e hizo croquis de los que después elaboró sus dibujos definitivos y probablemente los hizo en varias versiones.

Humboldt, quien seguramente conoció algunos de los originales de las manos de Castañeda, se expresó así en una carta fechada en 1826: "los dibujos de la expedición de Dupaix, de los que yo he conocido su escrupulosa exactitud. La ingenua simplicidad de los dibujos incluso, atestigua la verdad del testimonio". ${ }^{9}$ El juicio de Humboldt, sin embargo, no es muy de tomarse en cuenta pues el famoso naturalista alemán no conoció casi ninguno de los sitios y monumentos ilustrados por

6 Guillermo Dupaix, op. cit., 1969, p. 46.

7 Fausto Ramírez, op. cit., pp. 157-158.

${ }^{8}$ Guillermo Dupaix, op. cit., 1978, p. 62.

9 Citado por Alcina Franch en Dupaix, op. cit., 1969, p. 16. 
Castañeda. Otra opinión contemporánea es la de Charles Farcy, miembro de la Real Sociedad de Anticuarios de Francia, quien califica a nuestro dibujante de "diseñador ingenuo, poco versado en los secretos de la perspectiva". ${ }^{10}$

Hacia 1969, el Dr. José Alcina Franch encontró, en el Laboratorio de Arte de la Universidad de Sevilla, un manuscrito con el texto de Dupaix y 125 láminas con dibujos de Castañeda realizados a pluma y aguada. A este conjunto lo llama Alcina "Manuscrito de Sevilla" y se ha publicado con introducción y notas del propio Alcina. En su introducción nos dice:

El manuscrito... está compuesto de dos partes: las láminas y el texto. Las láminas que contienen los dibujos de José Luciano Castañeda se hallan reunidas formando un tomo encuadernado... precedidas del siguiente título general:

Colección de Laminas de los Antiguos monumentos de Nueva España, que comprende los tres viajes hechos por Real órden, por Don Guillermo Dupaix, Capitán retirado de Dragones de esta capital. Dibujadas y delinedas por don Luciano Cas. tañeda, en México. Año de 1820.

\section{Añade Alcina que}

son varios los indicios que nos llevan a pensar que el manuscrito de Sevilla es, en parte al menos, la forma definitiva de la obra de Guillermo Dupaix... que no llegó a completar su autor acaso nunca. En efecto, de esta forma definitiva, sólo se terminó completamente, la parte gráfica, es decir, el tomo de láminas realizado por Castañeda... ${ }^{11}$

Algunos autores han puesto en duda que los dibujos del Manuscrito de Sevilla sean los originales de Castaneda. Miguel León-Portilla, por ejemplo, señala que Isidro Ignacio Icaza, entonces Conservador del Museo de México, certificó que los dibujos que entregaba a Baradère eran originales de Castañeda. Pregunta León-Portilla si hubo varias copias hechas por el mismo artista, o si las láminas de Baradère pasaron después a Sevilla. ${ }^{12}$

De estos dibujos a tinta, que considera originales de Castañeda, nos dice Alcina que "el dibujo es torpe y está lleno de defectos de perspectiva" y añade que son, sin embargo, más apegados a la realidad. ${ }^{13}$ Igna-

10 Charles Farcy en "Discurso Inicial" a Guillermo Dupaix, Antiquités Mexicaines, Relation de trois expeditions du capitaine Dupaix ... Jules Didot, París, 1834, p. xii.

11 José Alcina Franch en Dupaix, op. cit., 1969, p. 28.

12 Miguel León-Portilla en Dupaix, op cit, 1978, p. 10.

13 José Alcina Franch en Dupaix, op. cit., 1969, p. 15. 
cio Bernal coincide en que estos dibujos son de menor calidad pero de mayor exactitud que los grabados publicados. ${ }^{14}$

Después de revisar estos dibujos atribuidos a Castañeda (figs. 17 y 18) encuentro que muchos de ellos son de muy baja calidad, inexplicable en la obra de un "profesor de dibujo y arquitectura". Son, además, tanto o más inexactos que los grabados que ilustran las ediciones europeas de los viajes de Dupaix. Si estos dibujos realmente son originales de Castañeda, no pueden ser achacados a los grabadores muchos de los errores de interpretación; el origen está en los propios dibujos. Además, quedaría muy clara la frase "ingenua simplicidad" usada por Humboldt para describir los diseños de Castañeda, así como los calificativos de Farcy: "diseñador ingenuo, poco versado en los secretos de la perspectiva". Sabemos, también, que se hicieron copias de los dibujos y considero que no hay bases suficientes para afirmar con absoluta certeza que algunos de ellos sean los originales de Castañeda. Posteriormente regresaremos al tema de los dibujos de nuestro artista.

De regreso a la Ciudad de México en 1807, después de terminar la tercera expedición que los llevó hasta Palenque, Dupaix y Castañeda se dedicaron a ordenar sus materiales, a la redacción definitiva del informe y a la elaboración de los dibujos terminados. Antes de que se completaran estos trabajos estalló la guerra de Independencia por lo que probablemente el informe no pudo ser enviado oportunamente a España. Al morir Dupaix en 1817, todo el material quedó en poder de Castañeda quien lo depositó en el Museo de Historia Natural de la Ciudad de México, de donde posteriormente pasaría al Museo Nacional Mexicano fundado en 1825 en un local del edificio de la Universidad.

En 1831 se publicaron en Londres, en el volumen IV de la monumental obra Antiquities of Mexico editada por Lord Kingsborough, las láminas basadas en los dibujos de Castañeda con el título de "Monuments of New Spain, by M. Dupaix. From the Original Drawings executed by order of the King of Spain". Los grabados para esta edición fueron elaborados por A. Aglio. El texto de Dupaix aparecería poco después en el volumen VI de la misma obra Antiquities of Mexico. Tanto el texto, como las ilustraciones, seguramente provienen de una copia tomada de los originales en México que hacia 1820 consiguiera Latour-Allard quien, antes de la aparición de la edición de Lord Kings-

14 Ignacio Bernal, A History of Mexican Archaeology. Londres, Thames and Hudson, 1980 , p. 100. 


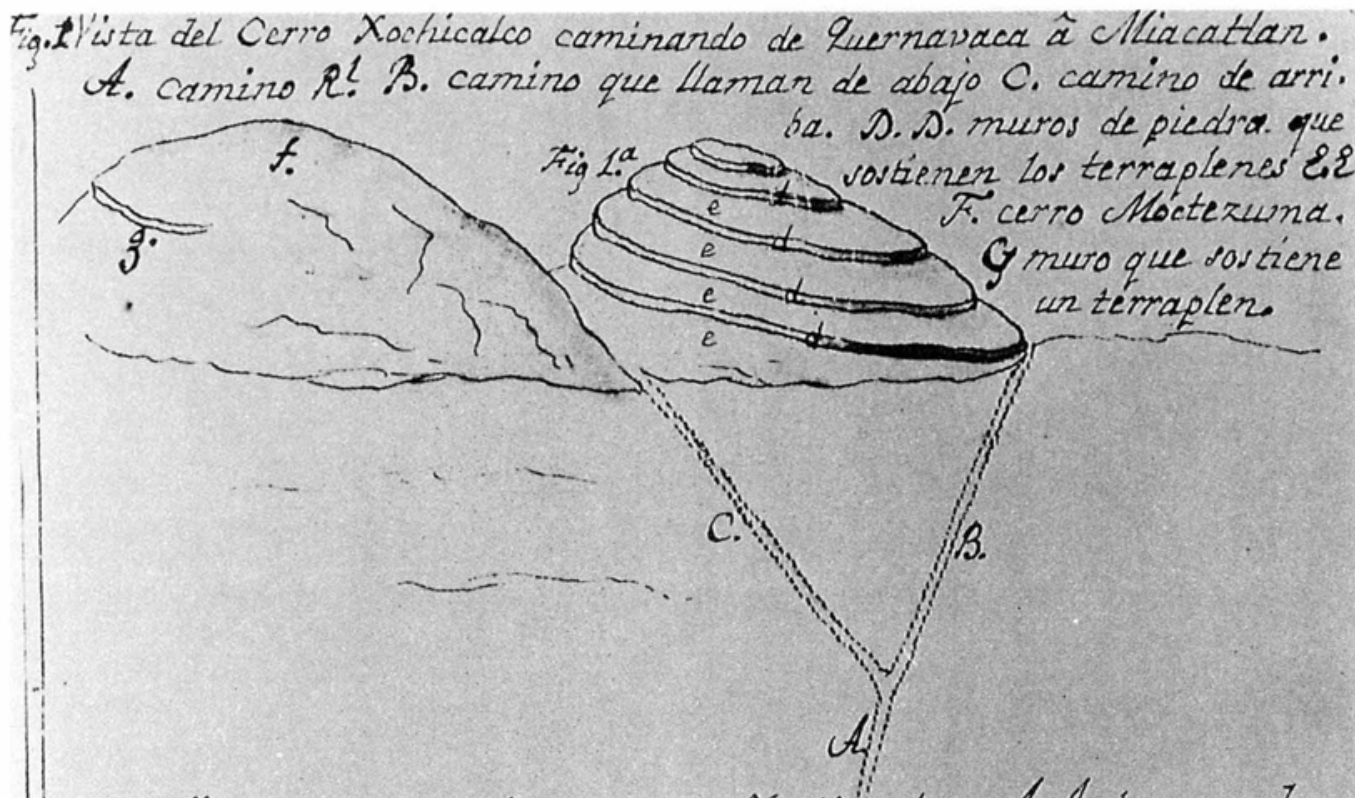

Fia. 2. Vista en prespectiba del Cerro Xochil calco. A A. terraza heira a mano. B. B. Castillo. C.C. paredies que vortiener los terraolenes. D. D. 2.\&. foro hecho à mázo que rodea al Cerro.

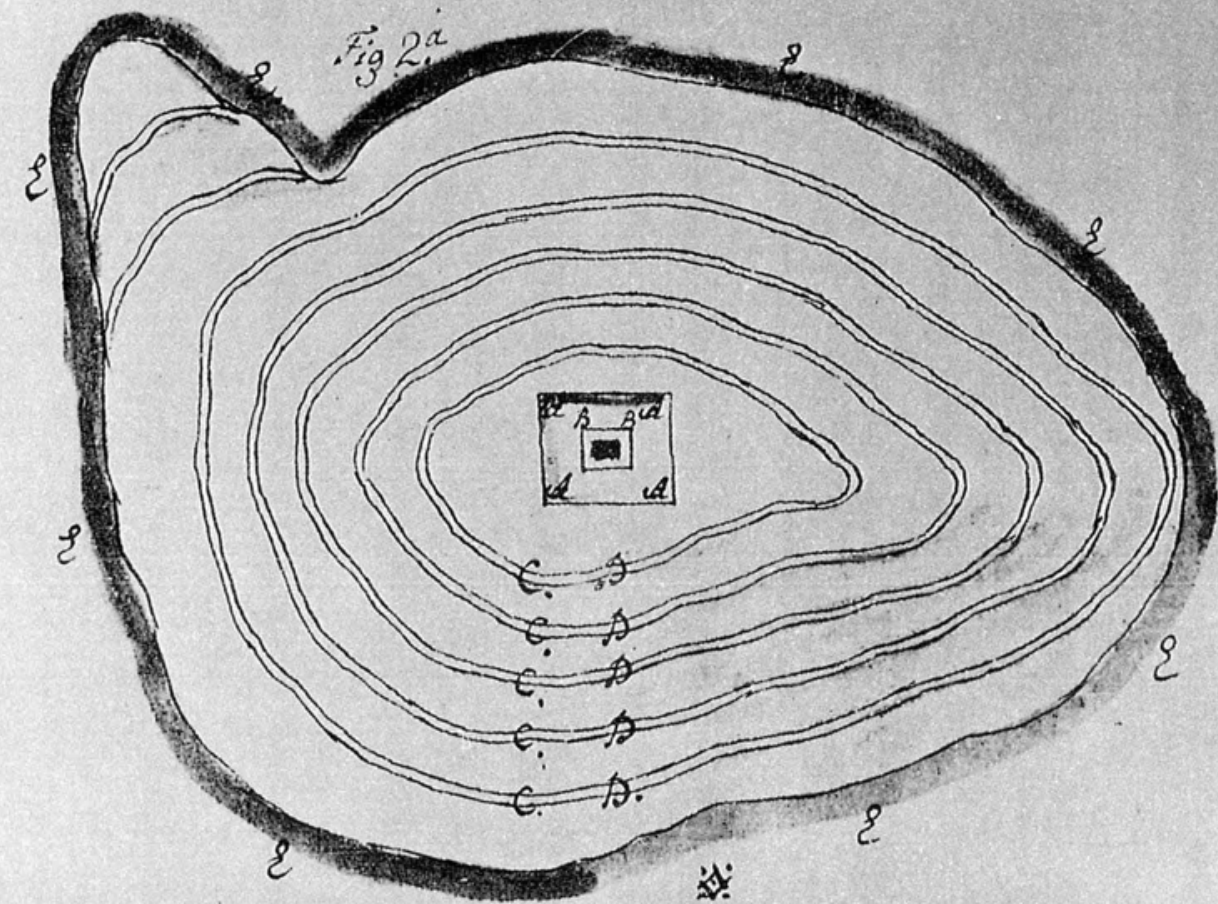

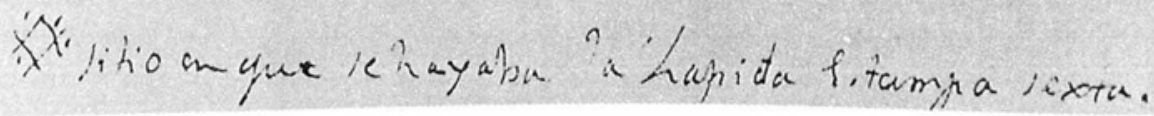

1. Vista General del sitio y planta del Cerro Xochicalco. Dibujo en el manuscrito de Alzate de 1777. Original en el Archivo del Museo Peabody, U. de Harvard. 


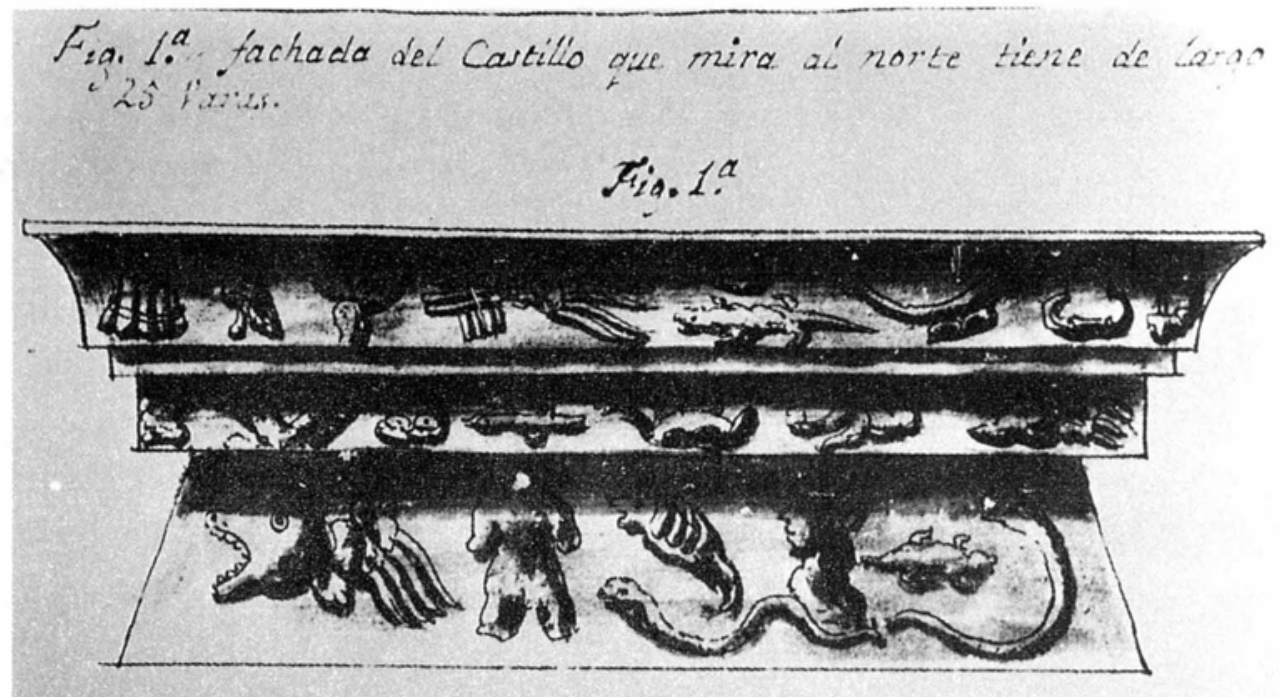

Fia. 2: fachada del oste, tiene 21. Pasas, de altura, tiene este primer cuerpo 4. Varas.

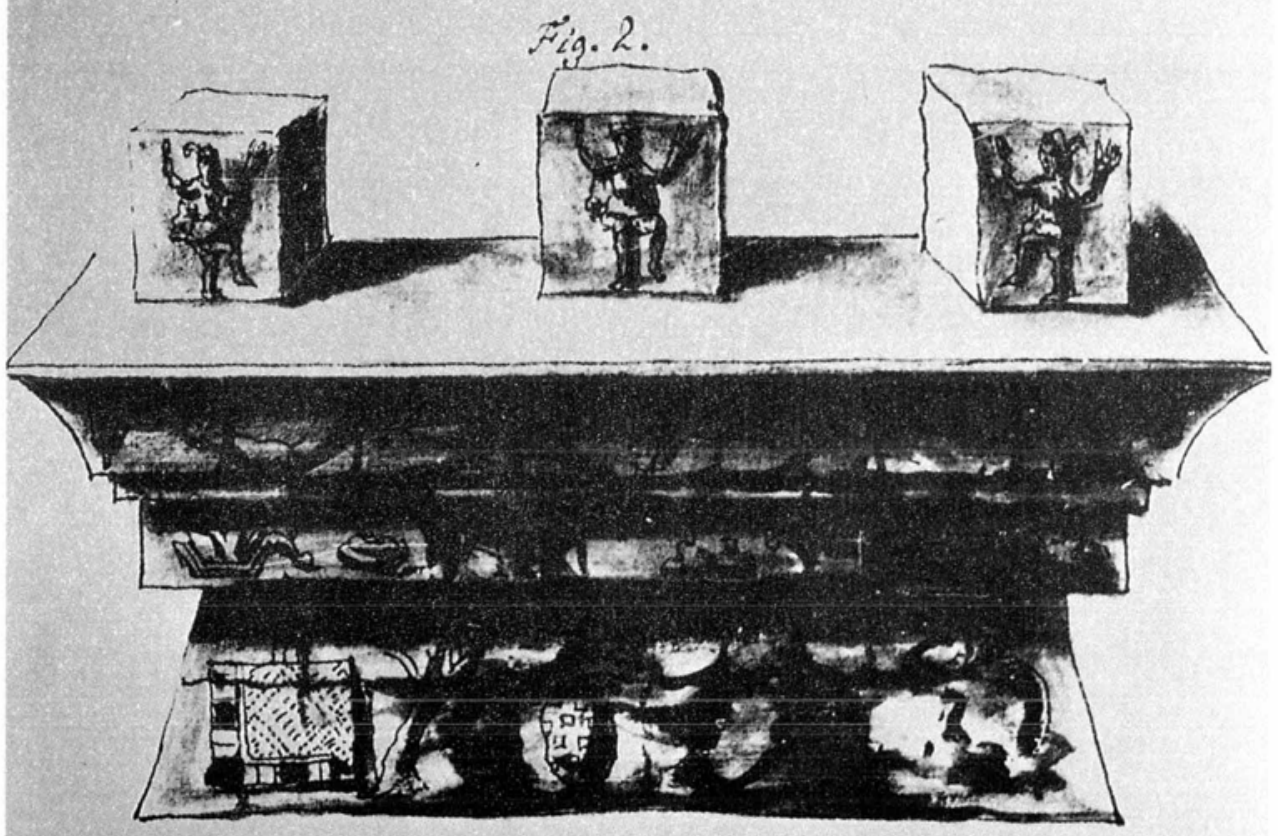

2. Fachada de la Pirámide de Xochicalco. Dibujo en el manuscrito de Alzate de 1777. 
ia tabrica del Caitillo como se veia haora leinte arzos: iegun se'me $n a$ inforinado por los dile sia aques tiempo lo registriaron. Se componia de S. cuerpos. A. Chimotiale ô cilla, era de pieclia de especial construccion.

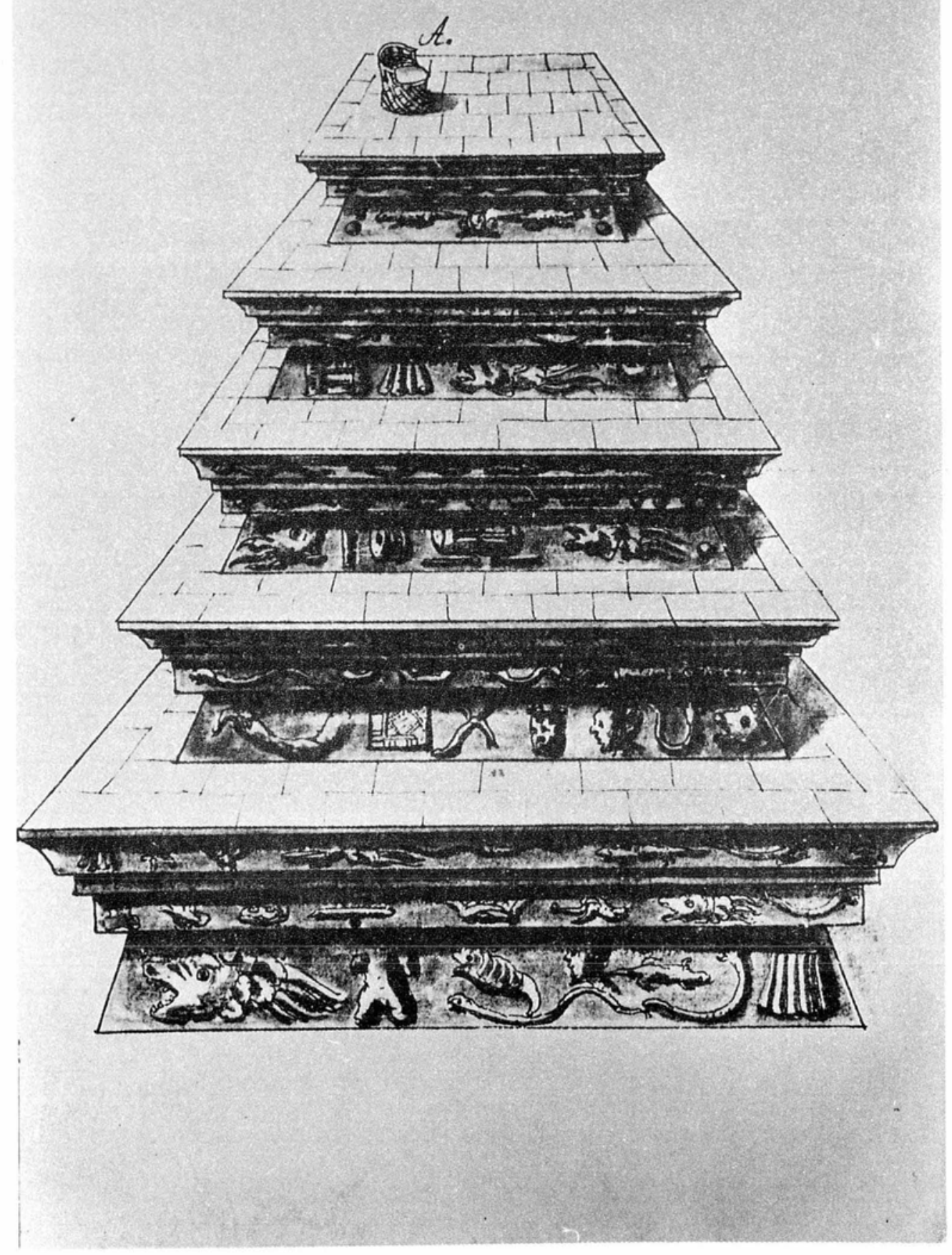

3. Reconstrucción hipotética de la pirámide de Xochicalco. Dibujo en el manuscrito de Alzate de 1777. Acerca de este dibujo, dice Alzate en el texto: "de esto no saldo por fiador; tan sólo estriba en informes de prácticos". 
DOI: http://dx.doi.org/10.22201/iie.18703062e.1991.62.1590

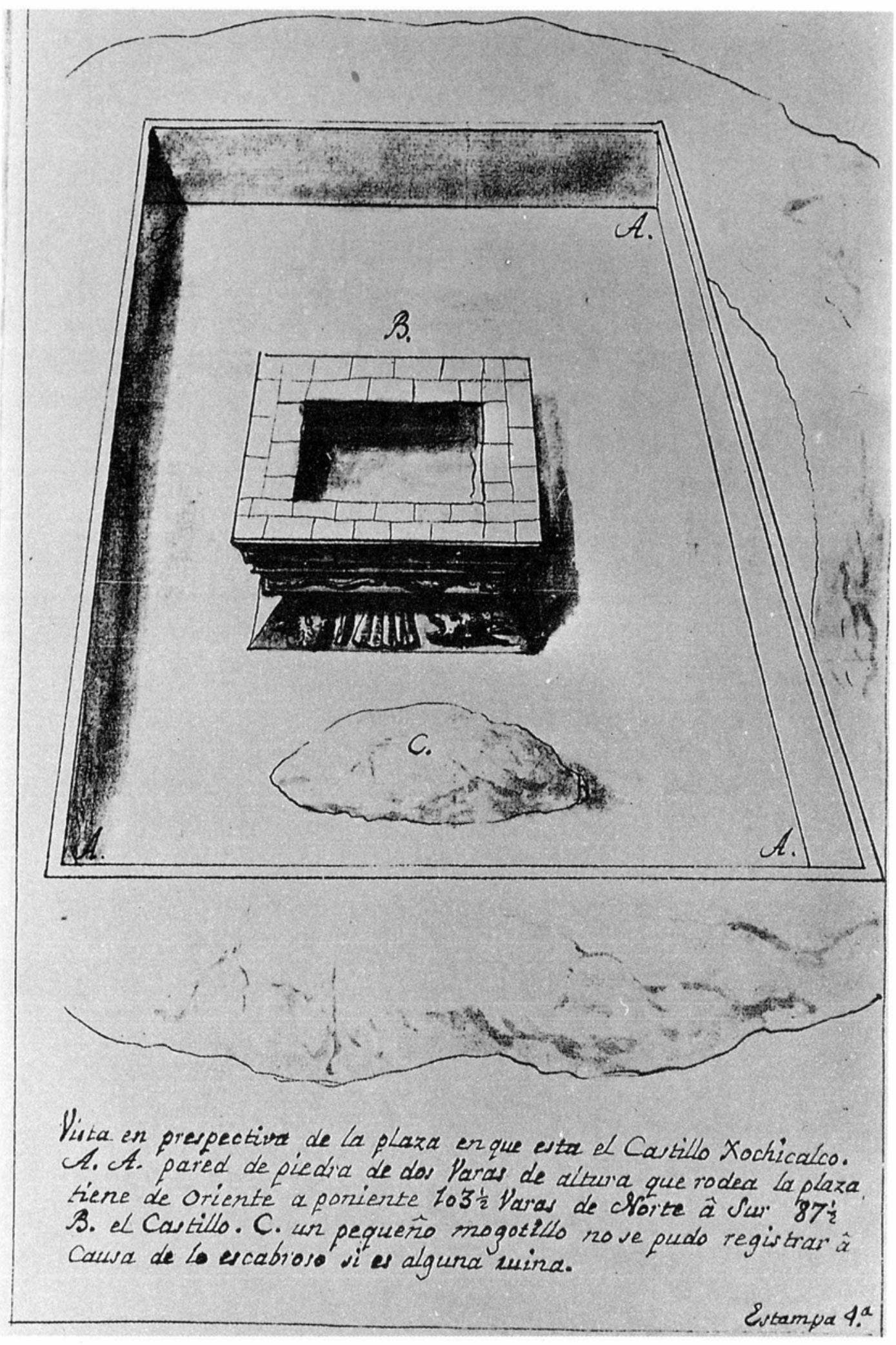

4. Vista de la plaza superior de Xochicalco. Dibujo en el manuscrito de Alzate de 1777. 


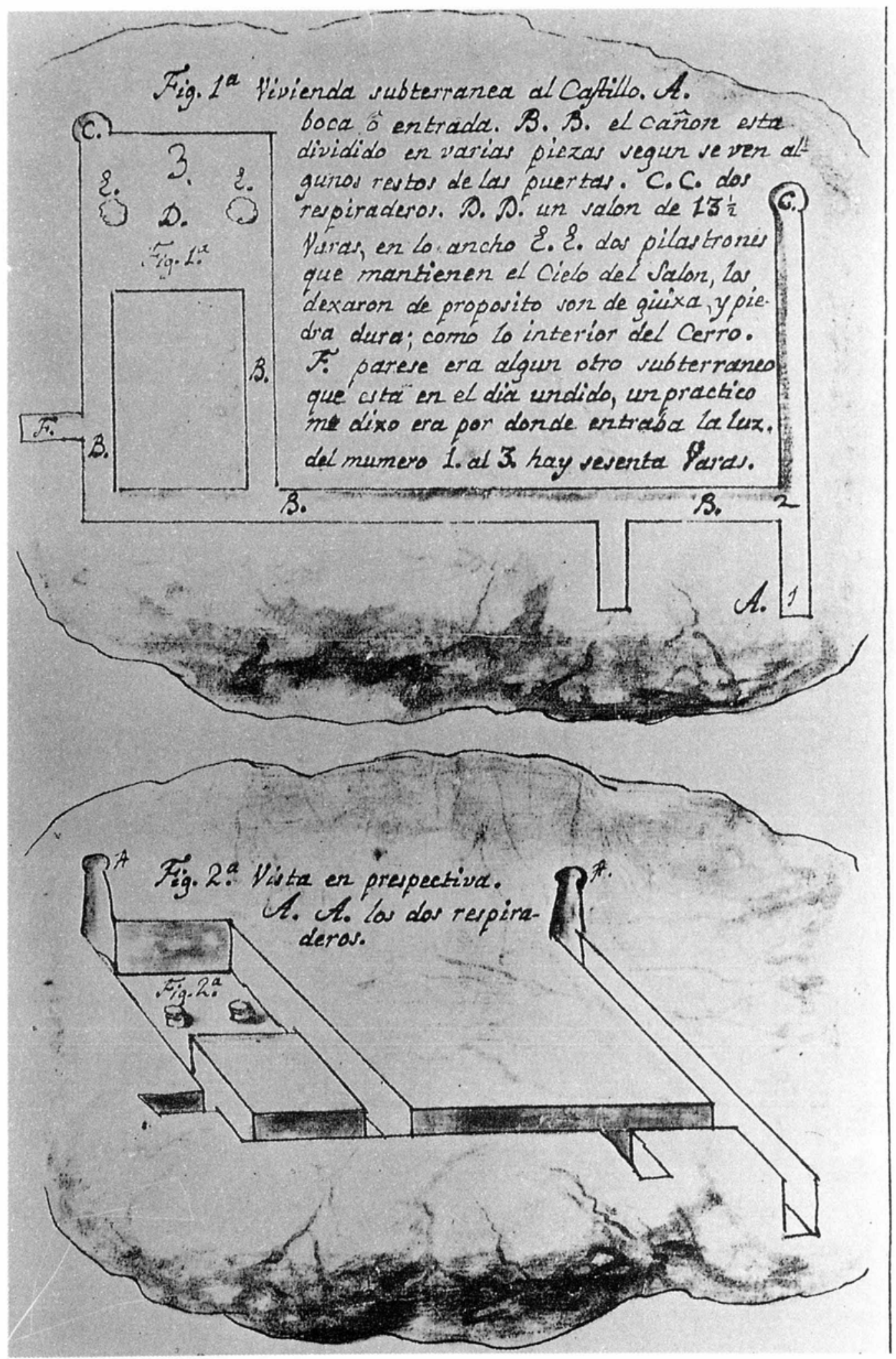

5. Planta y perspectiva de los "Subterráneos" en Xochicalco. Dibujo en el manuscrito de Alzate de 1777. 


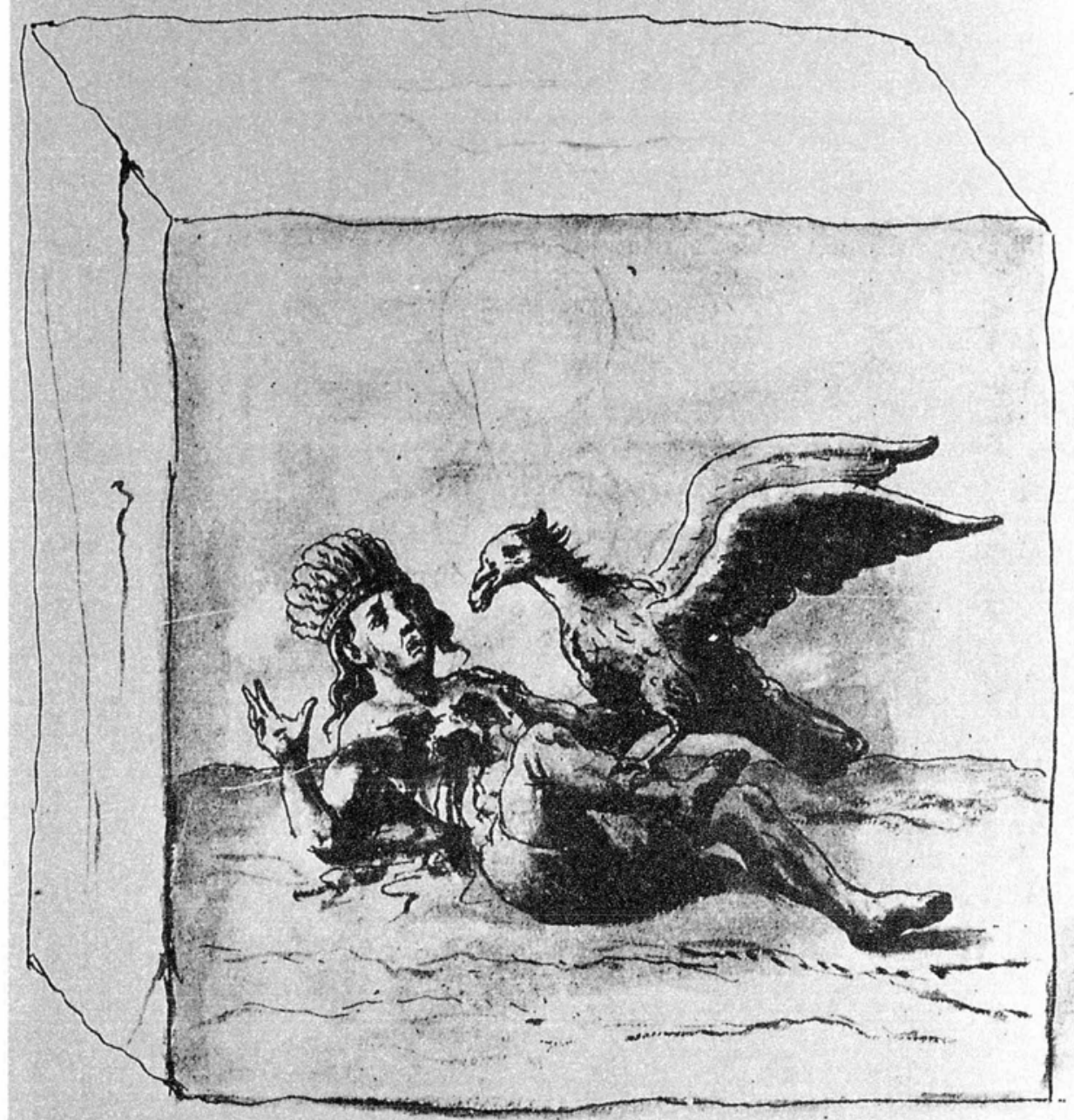

Lapida que ve hallava en el sitio $\mathrm{x}$. de la Estampa primera Fig. 2 :

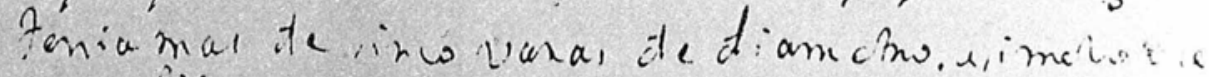

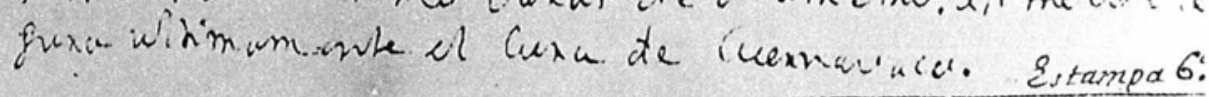

6. Lápida que según Alzate se encontraba en la base del Cerro de Xochicalco. Dibujo en el manuscrito de Alzate de 1777. 


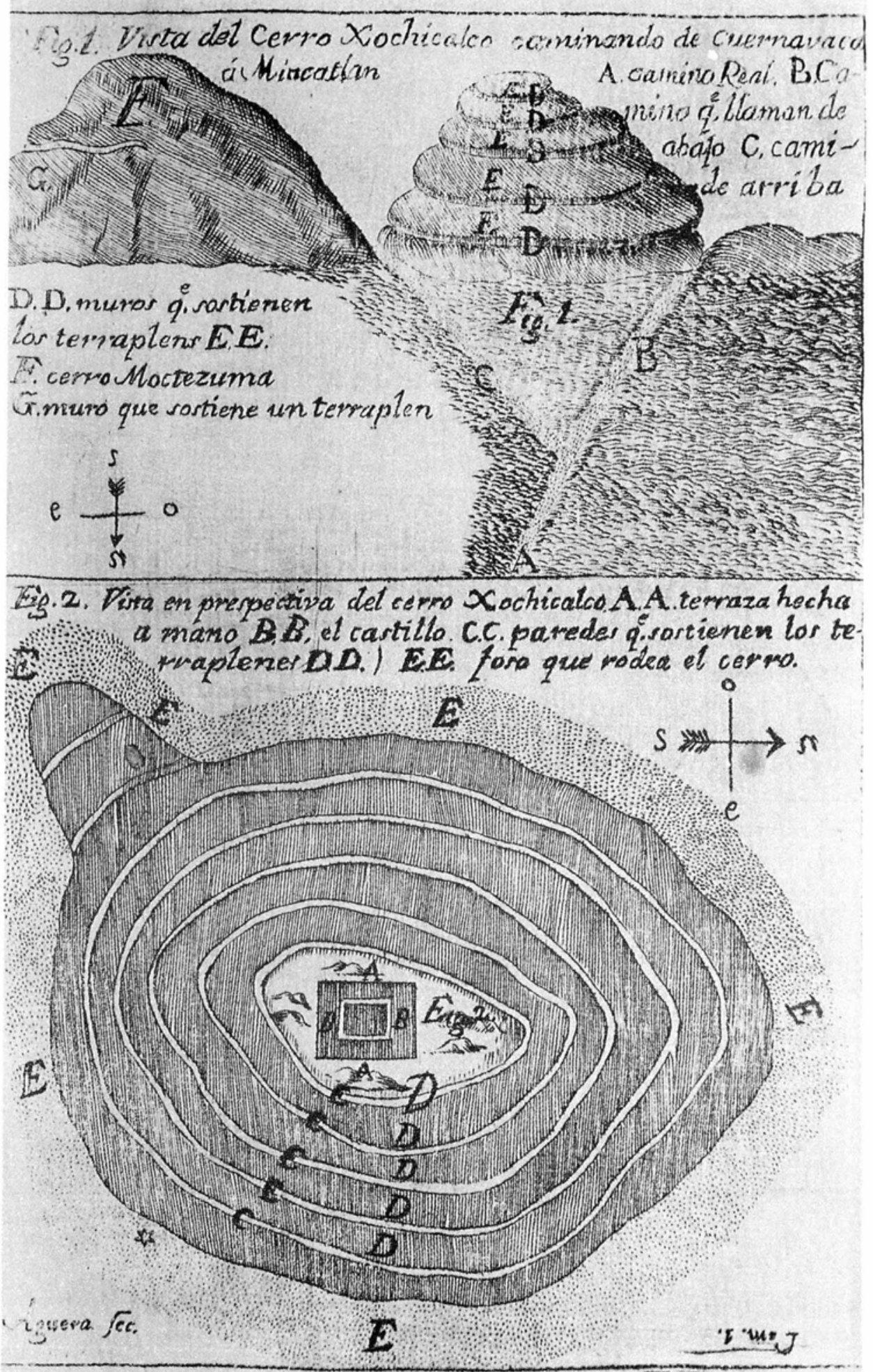

7. Vista general del sitio, y planta del Cerro Xochicalco. Grabado de Francisco Agüera publicado en el artículo de Alzate, 1791. 
DOI: http://dx.doi.org/10.22201/iie.18703062e.1991.62.1590

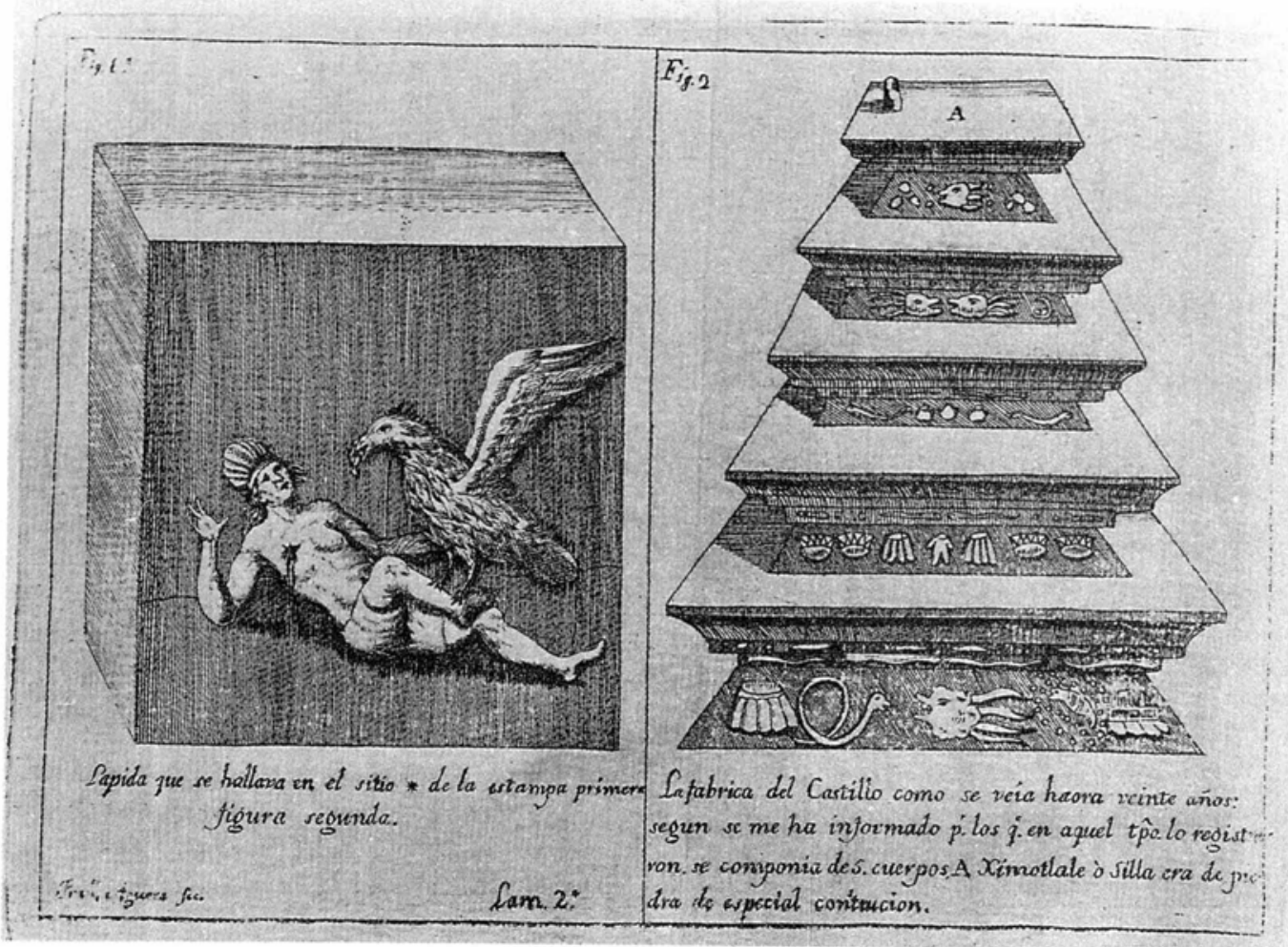

8. Lápida y reconstrucción hipotética de la pirámide de Xochicalco. Alzate, 1791.

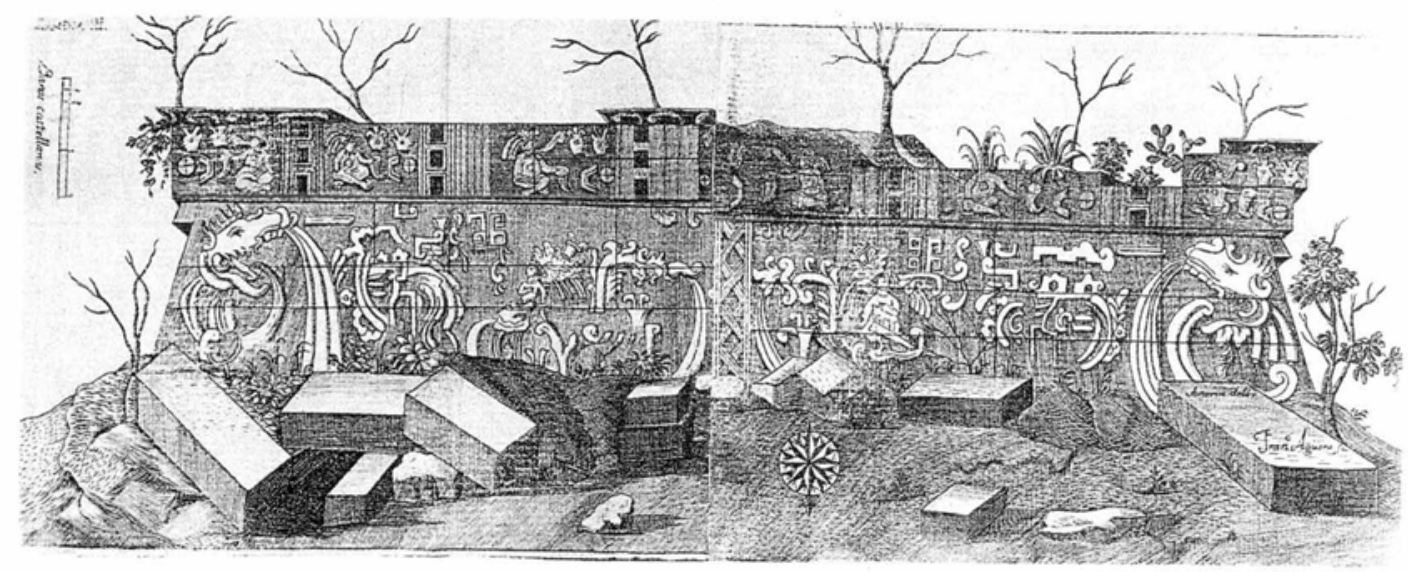

9. Fachada de la pirámide de Xochicalco. Alzate, 1791. 
DOI: http://dx.doi.org/10.22201/iie.18703062e.1991.62.1590

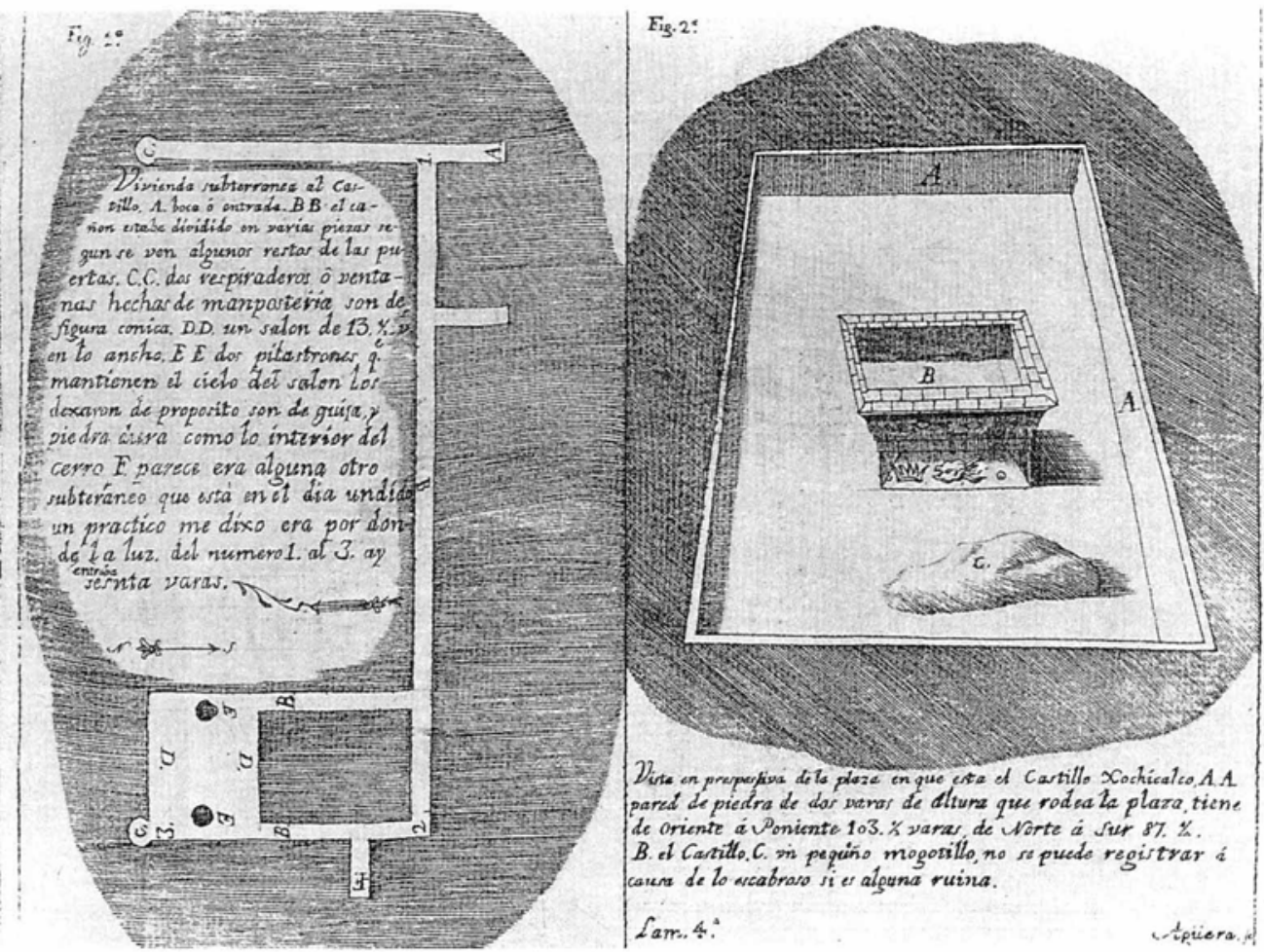

10. Planta de los "Subterráneos" y planta de la plaza Superior en Xochicalco. Alzate, 1791.

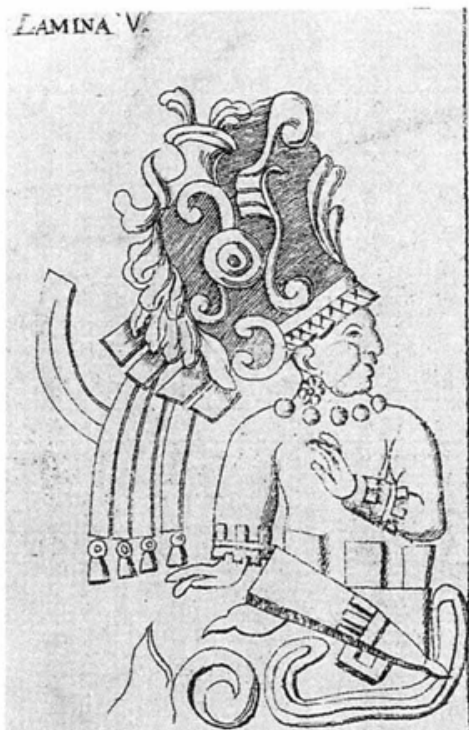

Esta representa por mayor á las que se ven sobre tas letes A A de ia Lamina 3

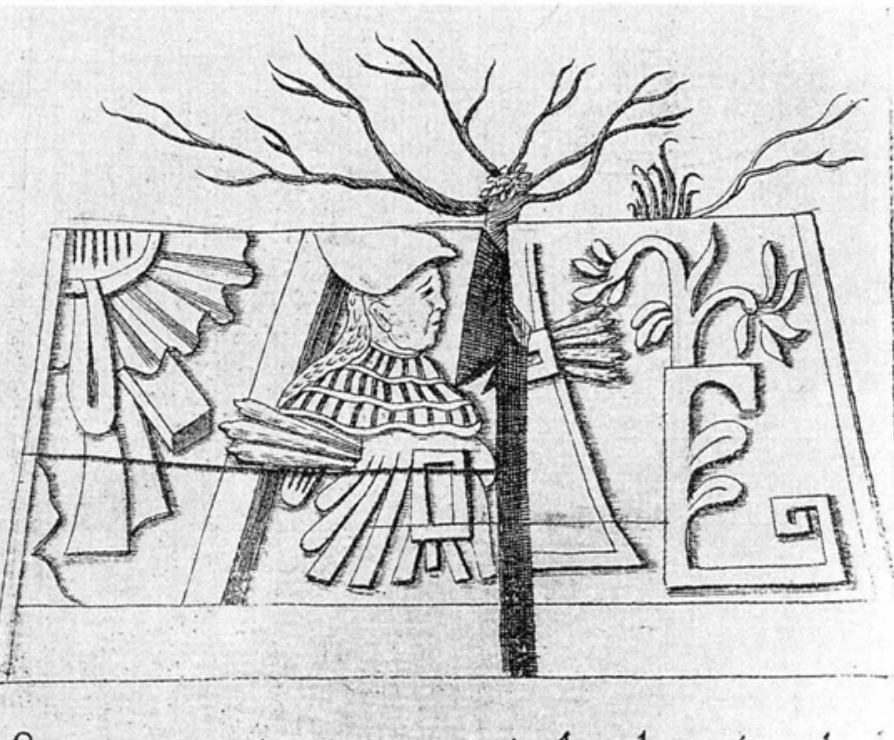

Erquina del seguendo Curra que está al sudoeste tiene de ai teria das baras, y quasts.

Aguesa. in

11. Detalle de los relieves, cuerpo superior de la pirámide de Xochicalco. Alzate, 1791. 
DOI: http://dx.doi.org/10.22201/iie.18703062e.1991.62.1590
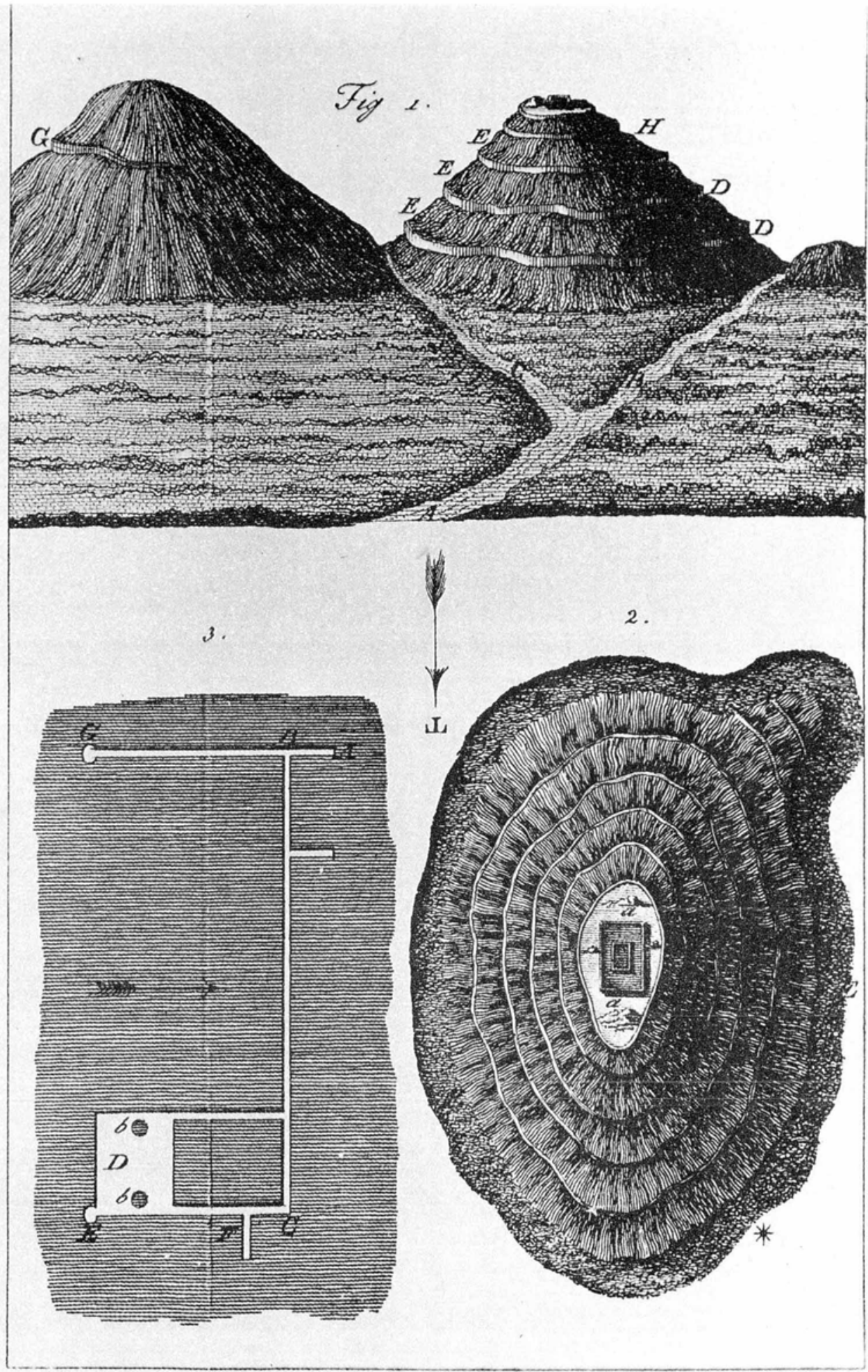

12. Vista general, planta del cerro y planta de los "Subterráneos", Xochicalco. Grabado en Márquez, Dos Monumentos... Roma, 1804. 
DOI: http://dx.doi.org/10.22201/iie.18703062e.1991.62.1590

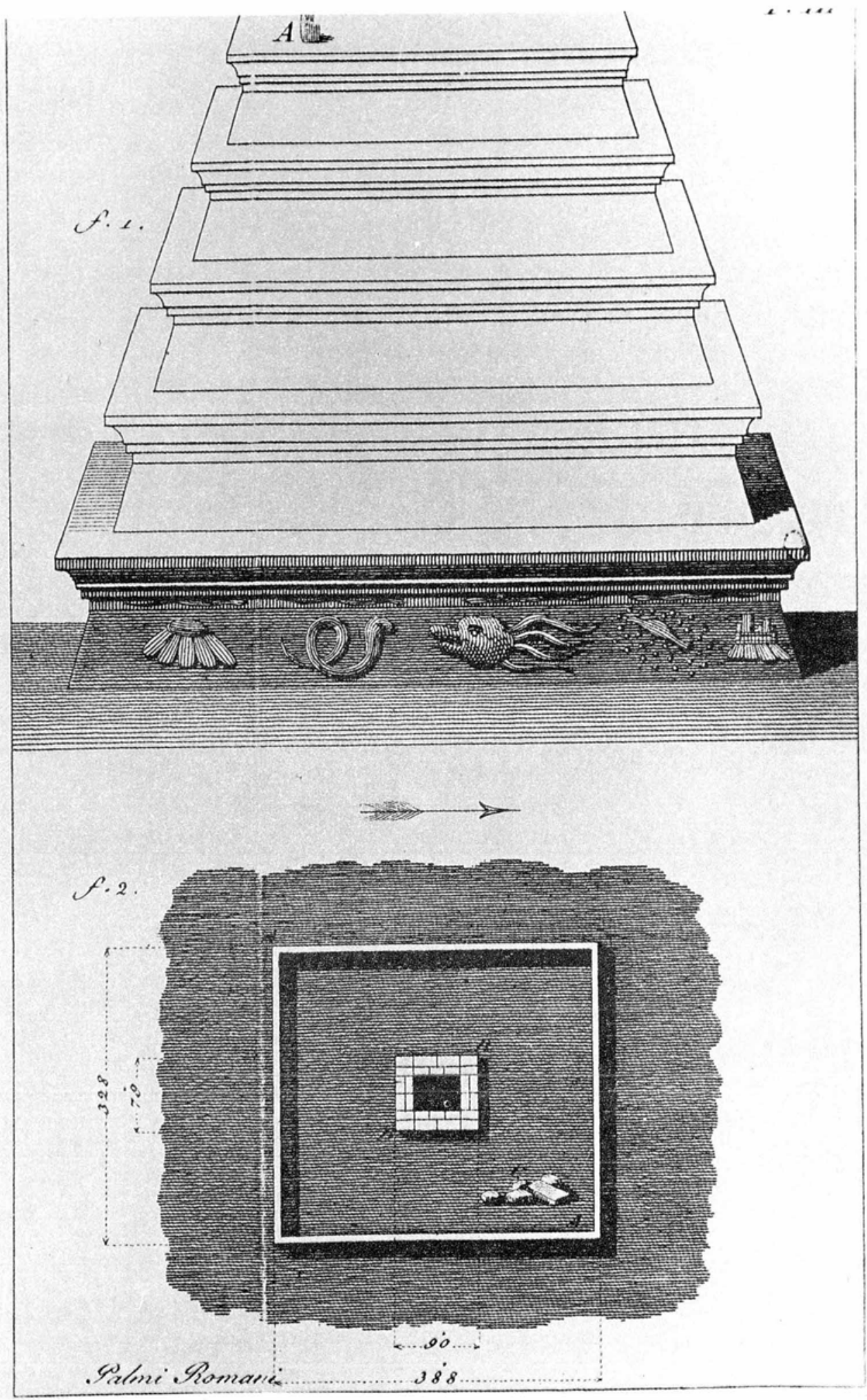

13. Reconstrucción hipotética de la pirámide y planta de la plaza de Xochicalco. Grabado en Márquez, Dos Monumentos... 1804. 

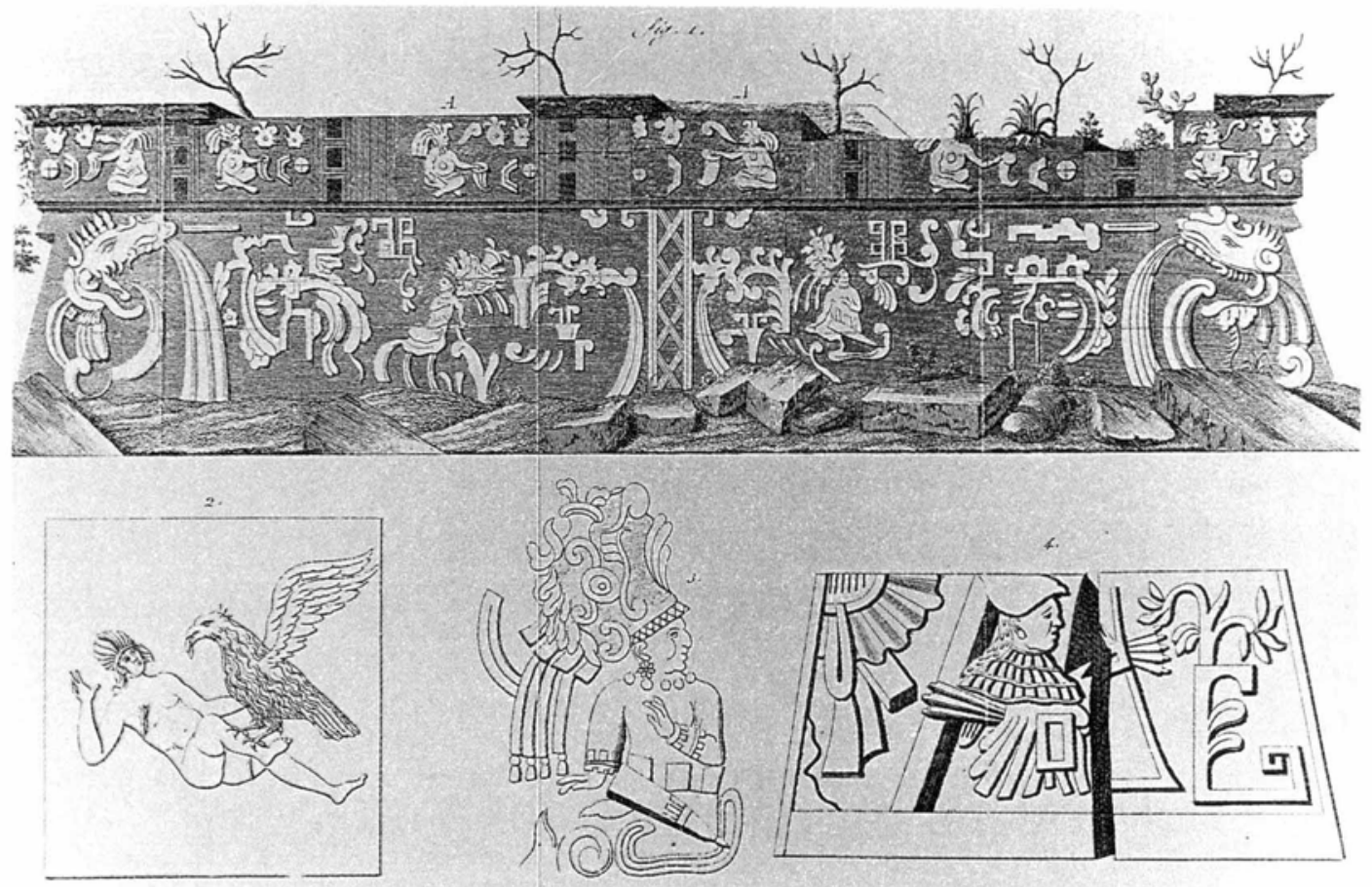

14. Fachada de la pirámide, lápida y detalle de los relieves en Xochicalco. Grabado en Márquez, Dos Monumentos... 1804.

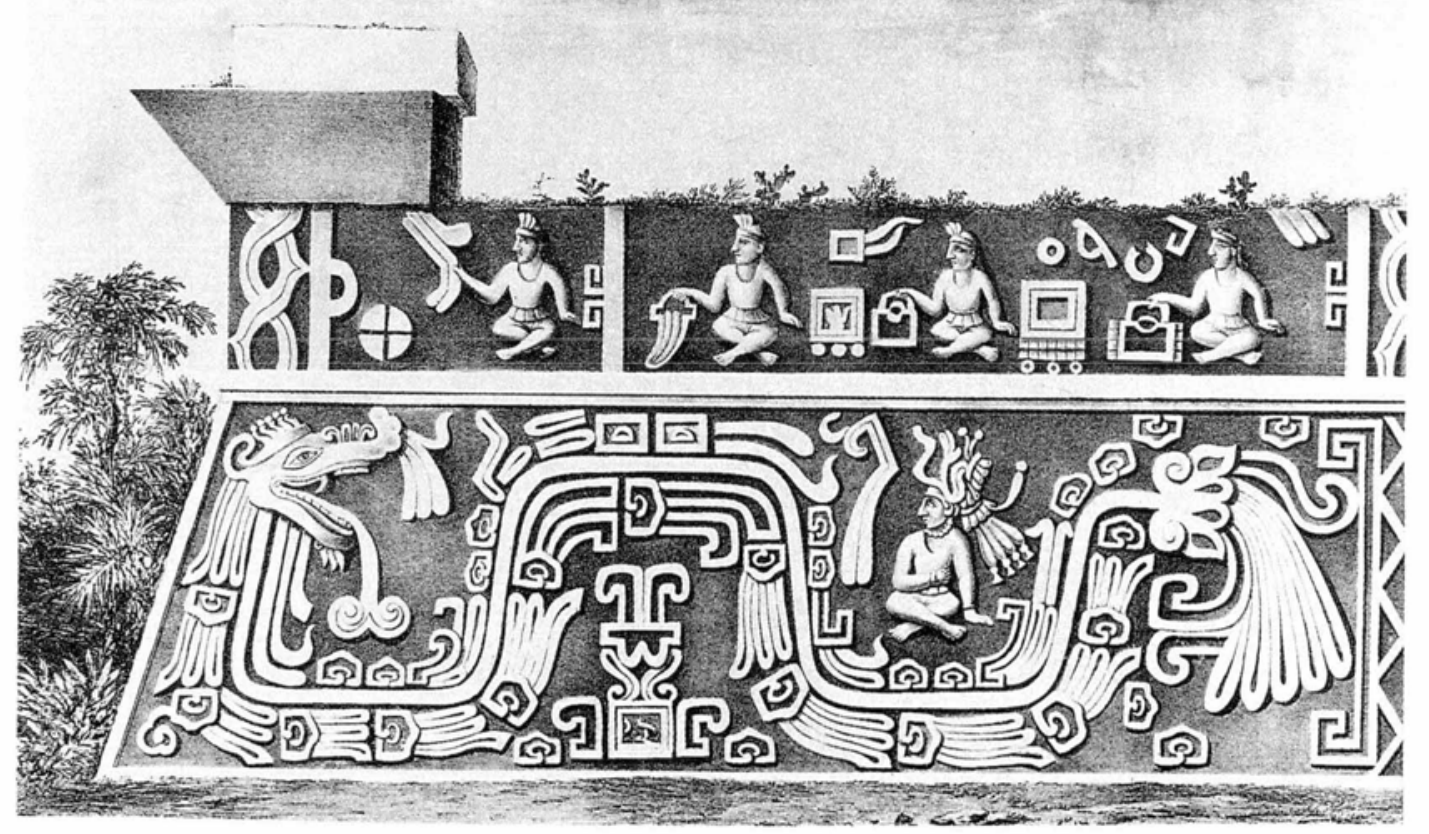

15. Fachada de la pirámide de Xochicalco. Ilustración atribuida a Castañeda, en Dupaix, 1834. Edición Kingsborough. 


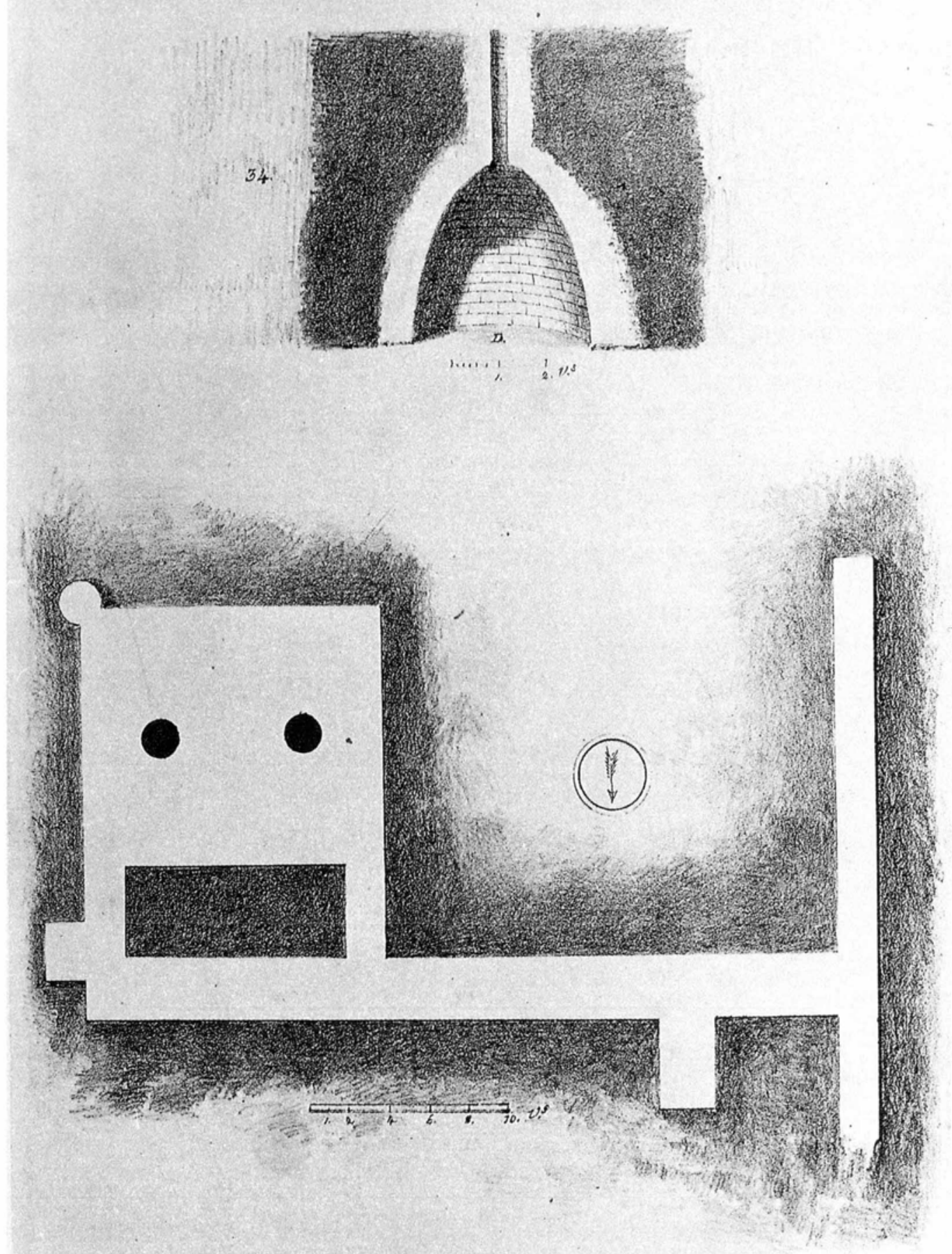

16. Planta de los "Subterráneos", corte del respiradero en Xochicalco. Ilustración atribuida a Castañeda, en Dupaix, 1834. Edición Kingsborough. 
DOI: http://dx.doi.org/10.22201/iie.18703062e.1991.62.1590

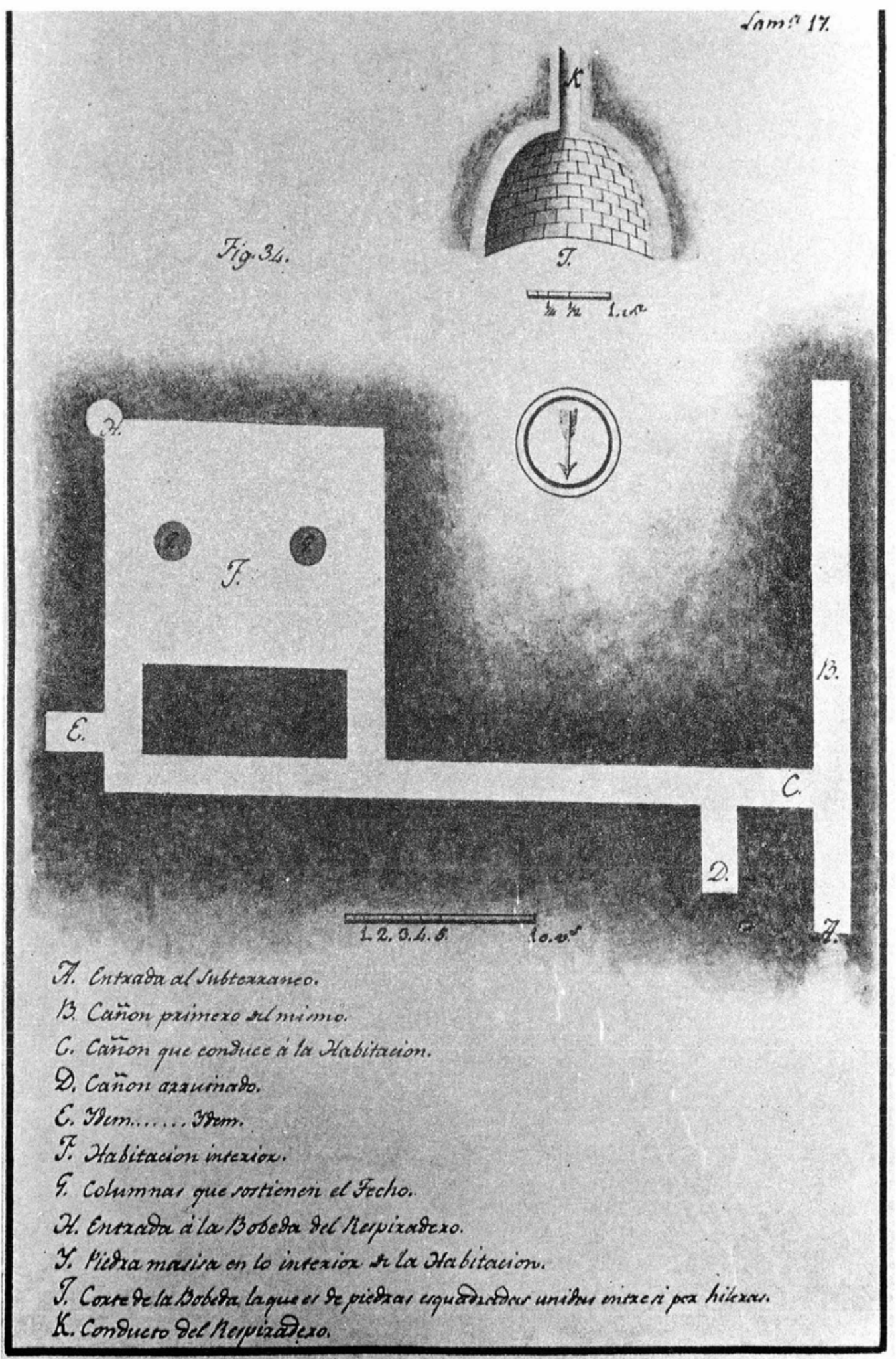

17. Planta de los "Subterráneos", corte del respiradero en Xochicalco. Dibujo en el Manuscrito de Sevilla. 


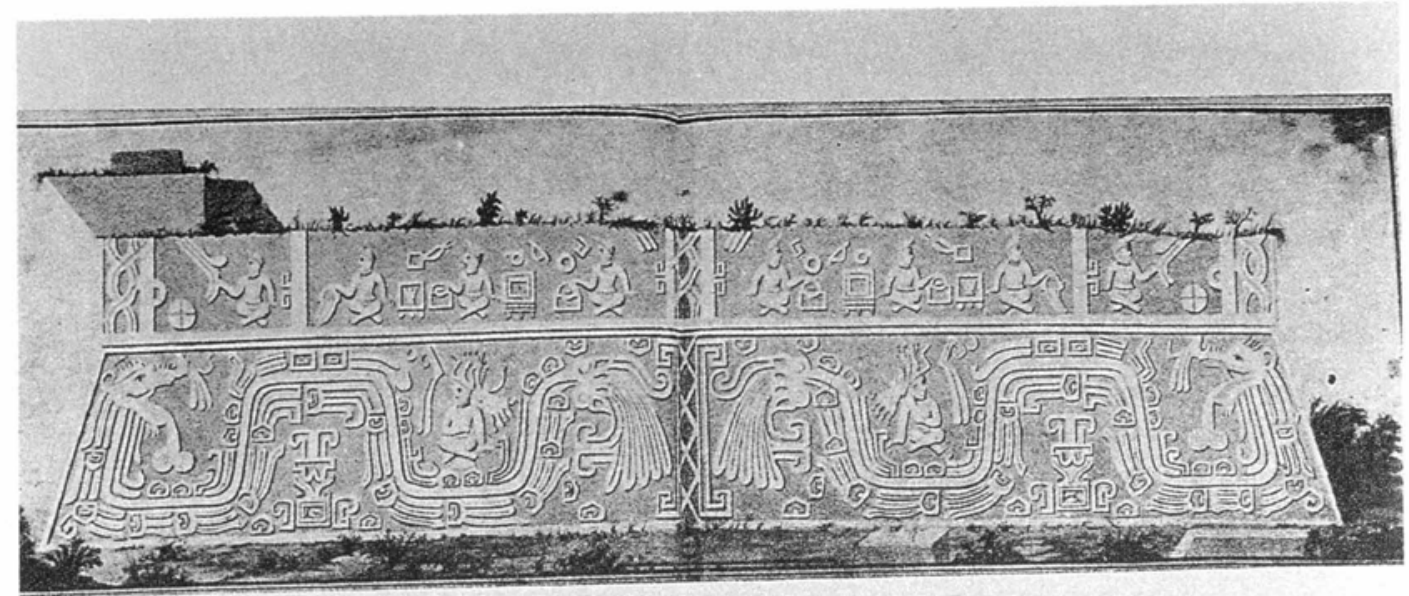

18. Fachada de la Pirámide de Xochicalco. Dibujo en el Manuscrito de Sevilla.

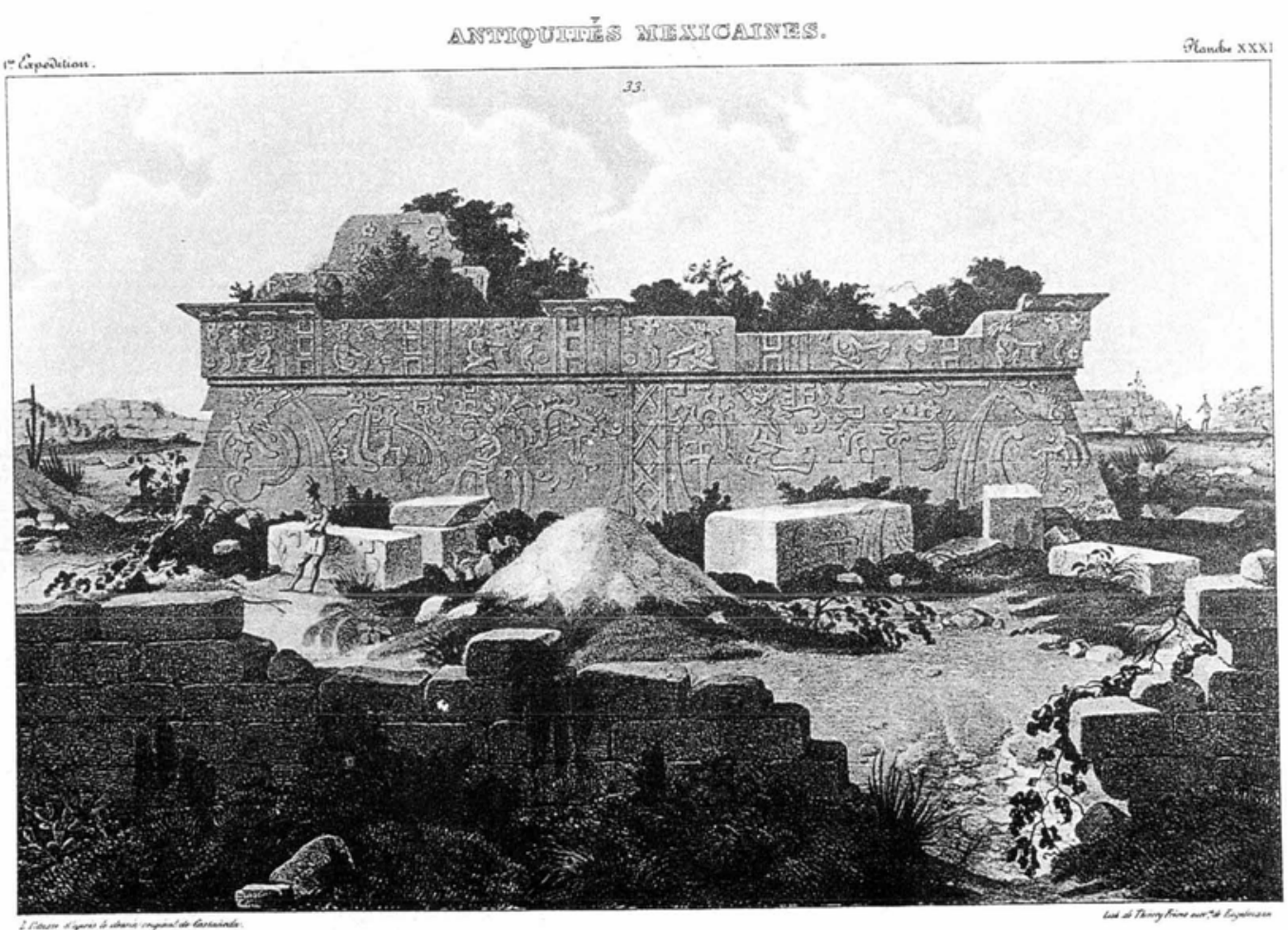

19. Fachada de la Pirámide de Xochicalco. Ilustración atribuida a Castañeda en Dupaix, 1834. Edición Baradère. Nótese la similitud con el grabado de Agüera (fig. 9) publicado por Alzate en 1791 y con el publicado por Márquez (fig. 14) en 1804. 
DOI: http://dx.doi.org/10.22201/iie.18703062e.1991.62.1590

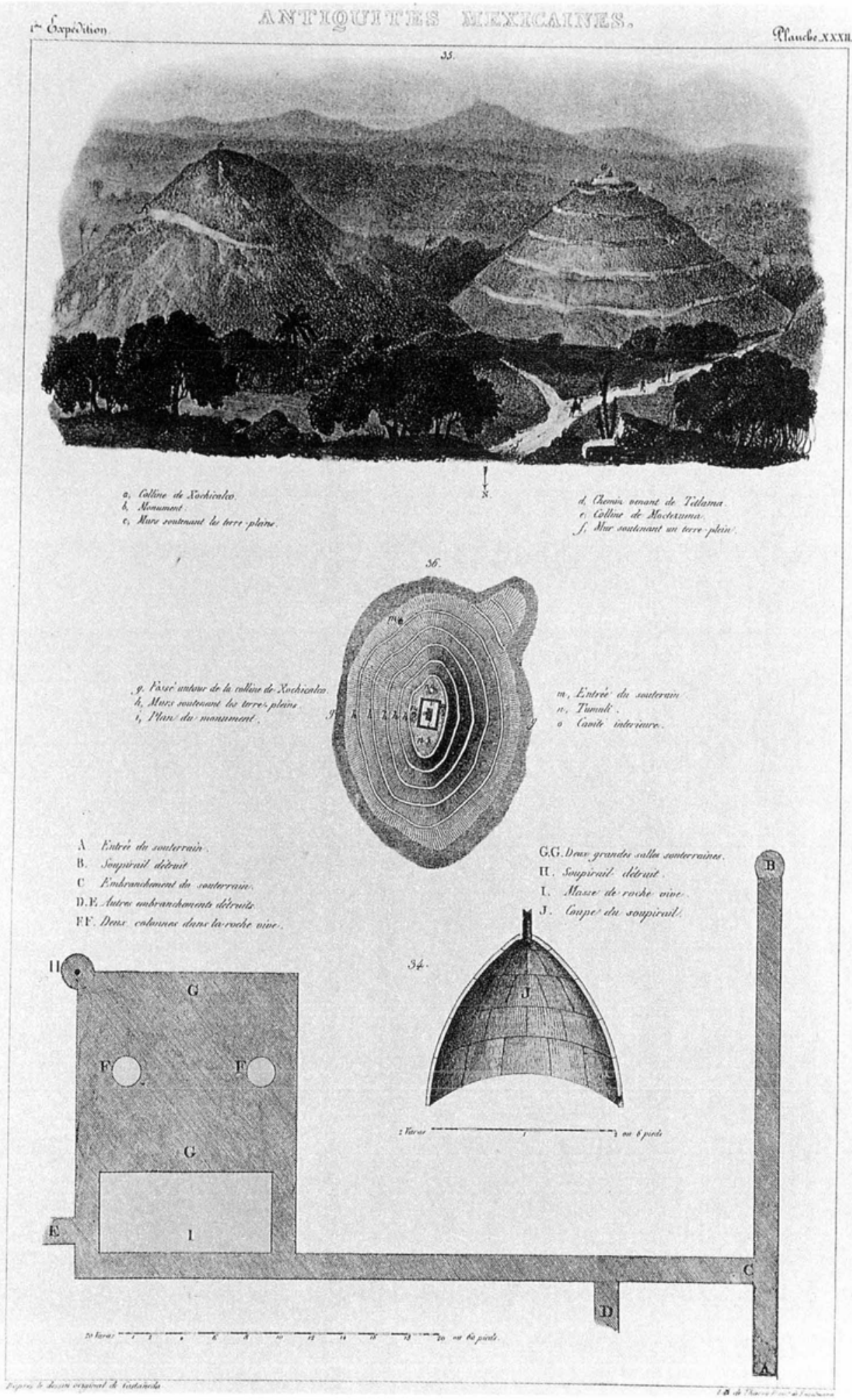

20. Vista general y planta del Cerro Xochicalco; planta de los "Subterráneos" y corte del respiradero. Ilustración atribuida a Castañeda en Dupaix, 1834. Edición Baradère. Nótese la correspondencia con los grabados de Alzate, 1791 y en Márquez, 1804. 
borough, había publicado algunas de las láminas de Castañeda sin ningún texto.

Mientras tanto, Jean-Henri Baradère, un abate francés, había venido a México en relación a una empresa que pretendía fundar una colonia francesa en las márgenes del río Coatzacoalcos y lograr comunicación entre los dos océanos por el istmo. Baradère se interesó por las antigüedades mexicanas y en sus búsquedas se encontró, en 1828, con el manuscrito de Dupaix y los dibujos de Castañeda que permanecían en el Museo Nacional. Fue tal su entusiasmo que pidió autorización oficial para hacer exploraciones en la zona maya de donde regresó con un buen número de piezas arquológicas. De acuerdo con la ley entonces vigente, podía haber conservado la mitad de su colección pero prefirió, o se le obligó, a entregarla toda a cambio de una serie completa de ilustraciones de Castañeda y una copia del relato de Dupaix, todo ello certificado como original por D. Isidro Ignacio Ica$\mathrm{za}$, el entonces conservador del Museo Nacional.

Estos son los materiales que Baradère envió a Francia y que sirvieron para la lujosa edición de los viajes de Dupaix que, en 1834, publicara el mismo Baradère en París con el título de Antiquités Mexicaines. Relation des trois expeditionas du capitaine Dupaix, ordonnés en 1805, 1806 et 1807 pour la recherche des antiquités du pays notament celles de Mitla et de Palenque. Para esta edición los dibujos de Castañeda fueron reelaborados y grabados por algunos de los mejores ilustradores europeos de la época. Es esta edición la más conocida y la que más se ha usado para valorar la obra de Dupaix y Castañeda.

Mi interés en la arquitectura de Xochicalco, el importante y bello sitio arqueológico del Estado de Morelos, me llevó a revisar detenidamente las descripciones e ilustraciones que de este interesante sitio hicieron cronistas y viajeros desde su descubrimiento en 1777 , incluyendo, por supuesto, la obra de Dupaix y Castañeda. Antes de analizar el trabajo de éstos, sin embargo, sería conveniente mencionar brevemente lo que de Xochicalco se había dicho antes de la visita de nuestros dos viajeros.

El primer visitante y cronista de Xochicalco fue don Antonio Alzate quien en 1777, y posteriormente en 1784, visitó el sitio e hizo una relación y descripción en su artículo "Descripción de las Antigüedades de Xochicalco" publicado en 1791 en la Gaceta de Literatura, que él mismo editaba en la Ciudad de México. Es aparente que Aizate no sabía de la existencia de Xochicalco y que su primera visita fue colateral a otros intereses, pues en su artículo dice: 
Estando por caminar al sur de México, procuré indagar de los prácticos las curiosidades que podrían encontrarse en aquellos paises. Se me advirtió por uno que registrase el castillo de Xochicalco... y ya desconfiaba de su informe cuando hallé ser cierta la existencia de esta preciosa antigüedad, y aunque... se me describía por una obra de cuantía mis esperanzas hallaron más de lo que solicitaba. Es obra opulenta y digna de todo aprecio, y no del abandono a que la han destinado. ${ }^{15}$

José Antonio Alzate Ramírez fue uno de esos criollos ilustrados que en el siglo XviII, junto con sus contemporáneos Antonio de León y Ga$\mathrm{ma}$, Francisco Javier Clavijero y otros ilustres mexicanos, siguiendo la pauta marcada cincuenta años antes por Carlos de Sigüenza y Góngora, hicieron renacer el interés en nuestro pasado prehispánico, contribuyendo con ello a la creación de un sentimiento de identidad y nacionalismo cultural. Su interés de anticuario y proto-arqueológico está muy relacionado con el origen de la mexicanidad. En su artículo, Alzate hace una vigorosa defensa de las civilizaciones prehispánicas y arremete contra aquellos "enemigos de la nación mexicana que quisieran ver extinguido aún el nombre mexicano" y contra "algunos aristarcos ridículos, que sin haber hecho estudio... de las antiguas costumbres de los mexicanos, los repudian de rústicos" ${ }^{16}$ En el mismo tenor se refiere, también, al "paradójico Conde Buffon y al sueco Bomare, que tratan a la antigua Nación Mexicana de ...ignorante y poco civilizada". ${ }^{17}$

Acerca de los monumentos arquitectónicos de civilizaciones antiguas, opina Alzate que éstas "sirven de grande recurso para conocer el carácter de los que los fabricaron... como también para suplir la omisión o mala fe de los historiadores. Un edificio manifiesta el carácter y cultura de la gente" ${ }^{18}$ Añade: "Si el celo indiscreto de algunos, y la codiciosa ignorancia de otros, no hubiesen destruido los monumentos mexicanos, se podría colectar una grande porción de antigüedades con qué averiguar ei legítimo origen de los indios, sus costumbres, su legislación... su comercio y ...se haría patente el que era una nación de las más poderosas del orbe" ${ }^{19}$ En estas frases se pone de manifiesto el interés de Alzate en la conservación de los monumentos prehispánicos como fuente importante para el conocimiento y valoración de las anti-

15 José Antonio Alzate, "Descripción de las Antigüedades de Xochicalco" "Gaceta de Literatura, Suplemento. México, 1791, p. 9.

16 Ibid., p. 2.

17 Ibid., p. 22.

18 Ibid., p. 1.

19 Ibid., p. 2. 
guas culturas prehispánicas. Lamenta la destrucción de los edificios de Xochicalco, que atribuye a la avaricia de los dueños de las haciendas de azúcar que usaron las piedras de los monumentos para hacer sus hornos, y se indigna contra "el primer destructor...un fulano Estrada... comparable al zapatero que quemó el templo de Diana Efesinal. iSu atrevimiento permanezca en oprobio para los amantes de la antigüedad! ${ }^{20}$

En su artículo, Alzate da una descripción detallada y, en general bastante precisa del sitio, basada en su recorrido y en lo que le contaron sus informantes; los errores de apreciación son explicables si se considera la brevedad de la visita y el estado en que se encontraban los edificios. Nos habla de "un cerro cuya superficie se halla fabricada a mano... [constando] de cinco terrazas o terraplenes, mantenidas por paredes de mampostería", y hace énfasis en el carácter militar del sitio, haciendo notar que "toda su circumferencia se halla rodeada de un foso hecho a mano". ${ }^{21}$

El sitio, nos dice Alzate, culmina con una gran plaza sobre la que se levanta "el Castillo", refiriéndose al edificio que ahora conocemos como Pirámide de las Serpientes Emplumadas. Describe y da las dimensiones de este edificio y considera que su "hermosísima arquitectura puede compararse a las pirámides de Egipto". ${ }^{22}$ El primer cuerpo de este monumento, informa, está "hermosísimamente labrado con jeroglificos mexicanos... exactamente labrados, de manera que el mejor cantero no es capaz de ejecutar obra superior" y opina que, "los esculpieron ya fabricado el castillo, porque de otro modo no era posible que los figurones que ocupan dos, tres o más piedras, guarden entre sí la bella disposición en que están". ${ }^{23}$ Basándose en los pocos restos que quedaban en pie del segundo cuerpo, deduce que era de similar estilo que el primero, y reporta que según le informaron los vecinos de Tetlama, el monumento originalmente consistía de cinco cuerpos escalonados, pero hace la advertencia de que de esto "no salgo por fiador; tan solo estriba en informes de prácticos ${ }^{n}{ }^{24}$

Alzate también describe los subterráneos y opina sobre su posible función, especula sobre el origen del sitio y la etimología del nombre

\footnotetext{
20 Ibid., p. 11.

21 Ibid., p. 10.

22 Ibid., p. 11.

23 Ibid, p. 12.

24 Ibid., p. 11.
} 
de Xochicalco. En general, y considerando el tiempo en que se escribió, el artículo es una magnífica monografía del sitio, y presenta valiosos comentarios sobre los monumentos y su valor histórico y estético, así como interesantes reflexiones de carácter antropológico e histórico.

Acerca de las ilustraciones que presenta el autor, debemos señalar que Roberto Moreno de los Arcos encontró en el archivo del Peabody Museum de la Universidad de Harvard, el manuscrito original de Alzate, que está acompañado de varios dibujos a tinta. ${ }^{25}$ Estos dibujos (figs. 1 a 6) especialmente los del monumento principal, son muy deficientes e inexactos; no hay siquiera el intento de representar verídicamente los relieves que cubren las fachadas del edificio. El maestro Moreno me ha hecho notar que los motivos que decoran el talud de la pirámide, en estos dibujos, probablemente fueron copiados del códice mexica "La Matrícula de Tributo" que ya había sido publicado por Lorenzana.

Los grabados que ilustran el artículo publicado en la Gaceta fueron realizados por Francisco Agüera (figs. 7 a 11). Aunque de mejor factura que los dibujos del manuscrito son, en su mayor parte, copia de los anteriores. Uno de los grabados, sin embargo, el que muestra la fachada oriente de la Pirámide de las Serpientes Emplumadas, aunque todavía con bastantes inexactitudes, es ya una versión muy aproximada a la realidad y puede considerarse el primer retrato formal del monumento, a pesar de que aún no se reconoce todavía el tema principal de los relieves: las serpientes emplumarlas, entre cuyas ondulaciones aparecen los personajes sentados a la oriental. Se aprecian únicamente las cabezas de estas serpientes a las que Humboldt, basándose en estos dibujos, pues no visitó el sitio, confundió con "cabezas de cocodrilo que arrojan agua" y se asombró de "ver que el arquitecto, en lugar de imitar las plantas y los animales conocidos por los pueblos montañeses, haya empleado en estos relieves... las gigantescas producciones de la zona tórrida". ${ }^{26}$

En 1804, el p. Peäro José Márquez publicó en Italia un artículo titulado "Dc: Monumentos Antiguos de Arquitectura Mexicana" que trata de Xochicalco y de la recién descubierta pirámide de El Tajín. Már-

25 Agradezco al Maestro Moreno de los Arcos el haberme informado de la existencia de este manuscrito y haberme permitido examinar fotografias de los dibujos que lo acompañan.

26 Alexandro de Humboldt, Descripción de las Cordilleras y Monumentos de los pueblos indigenas de América, México, Secretaría de Hacienda y Crédito Público, 1974, p. 58. 
quez no conoció Xochicalco pues fue expulsado de México con todos sus compañeros jesuitas en 1767, diez años antes de que Alzate realizara su primer viaje, y no regresó a México sino hasta 1816, a la edad de setenta y cinco años. Su artículo, como él mismo aclara, está basado en el texto y las ilustraciones publicadas por Alzate y no es extraño, por lo tanto, que su descripción del sitio coincida en todo con la de Alzate. Márquez, sin embargo, presenta sus propias interpretaciones acerca del origen y función del monumento y de su valor estético. Las ilustraciones, grabadas en Italia, fueron copiadas de las publicadas por Alzate (figs. 13 a 15).

Alexander von Humboldt, en su obra Vistas de las Cordilleras y Monumentos de los Pueblos Indigenas de América, publicada en París entre 1810 y 1813 , incluyó una breve descripción de Xochicalco y una lámina que ilustra la pirámide del sitio. Humboldt tampoco conoció Xochicalco, y dice que se basa en la descripción de Alzate y que la lámina está copiada de los dibujos de Agüera. El hecho de haber incluido a Xochicalco en su obra, confirió importancia a este sitio; varios de los visitantes y cronistas posteriores supieron de él a través de los escritos de Humboldt.

Cuando Dupaix y Castañeda llegaron a Xochicalco a mediados de 1805 , ya se habían publicado, como hemos visto, los artículos de Alzate y de Márquez.

Aunque Dupaix no hace mención del p. Alzate, ni de su artículo de 1791, tengo la impresión de que lo conocía. Dupaix, antes de iniciar sus exploraciones, se había documentado bien; además, coincide en muchas de las descripciones y en algunos de los errores de Alzate.

Coinciden en el carácter defensivo del sitio, un cerro aislado rodeado en su base por un foso artificial, así como en los terraplenes sostenidos por muros de mampostería. También, como Alzate, piensa que la plaza superior estaba cercada por una muralla de piedra de dos varas de altura que servía de parapeto. Inexplicablemente menciona que a esta plaza se sube por "una calzada con bastante declivio, de unas tres varas de ancho". ${ }^{27}$ Cualquier visitante a Xochicalco sabe que la calzada sube solamente hasta la plaza central y no se continúa a la plaza superior: aún no se ha localizado un acceso franco a esta plaza.

Acerca de la pirámide, opina que es "una famosa obra... oratorio o palacio... producción del ingenio de esta nación, en la que se dieron la mano y se combinaron arquitectura y escultura [y tiene] un aspecto se-

27 Guillermo Dupaix, op, cit., 1978, p. 64. 
rio y magestuoso que llena y satisface el entendimiento". ${ }^{28}$ Es el primero en mencionar la escalinata de esta pirámide, escalinata que no había sido reconocida por Alzate.

Acerca del tema de los relieves que cubren las fachadas, Alzate sólo había mencionado "jeroglíficos mexicanos" y "danzantes de medio relieve". Dupaix no intenta interpretar la iconografía pero observa que "las figuras, grabadas en gran relieve... representan variedad de objetos jeroglíficos de hombres, animales, plantas y otras que no se conocen" y se aproxima más a la realidad al confundir el cuerpo de la serpiente emplumada con "una especie de guirnalda continua y dominante, culebreando el paño de sus tres lienzos"; piensa que éste puede ser el origen del nombre Xochicalco: "casa-flor" ${ }^{29}$ Reconoce Dupaix el segundo cuerpo del edificio y considera que debió servir de habitación o templo y señala que los relieves que recubren la fachada son de diferente temática que aquellos de las fachadas del primer cuerpo.

Dedica bastante de su texto a la descripción de los subterráneos y señala que aún subsistían los enlucidos en muros, bóvedas y pavimentos, con restos de pintura de almagre. Menciona el salón con unas "pilastras cortadas en la misma roca" y se refiere a la boca del respiradero como "una cúpula de forma cónica de dos varas de diámetro...revestida de piedras cuadradas, puestas en filas circulares con mucha unión y limpieza". ${ }^{30}$

No me sorpendió demasiado el paralelismo que existe entre las descripciones de Alzate y las de Dupaix pues, como ya lo mencioné, creo que este último conocía el artículo del primero. Por ei contrario, al revisar la edición parisina de la obra de Dupaix, hecha por Baradère en 1834, mucho me sorprendió que las ilustraciones fueran casi idénticas a las hechas por Francisco Agüera para el artículo de Alzate de 1791.

Las láminas XXXI y XXXII que en la edición de Baradère corresponden a Xochicalco, tienen el pie de grabado "D'aprés le dessin original de Castañeda" (figs. 19 y 20). Sin embargo, estas ilustraciones son extraordinariamente similares a las ejecutadas por Agüera. Analicemos algunas de estas semejanzas que no pueden deberse a mera coincidencia.

En ambas ediciones, la vista general del sitio es casi idéntica, a pesar de la mejor calidad del grabado francés. Coinciden en el punto de vis-

29 Ibid.

80 Ibid., pp. 64-65. 
ta que muestra los dos cerros y la bifurcación del camino de Tetlama. Cabe aclarar que este punto de vista es convencional pues no existe al norte de Xochicalco ninguna elevación natural que permita esta panorámica. Los dos grabados coinciden, también, en la nomenclatura y en varios detalles que no son aparentes a simple vista, como lo son el número de terrazas del cerro de Xochicalco, el muro de contención en el cerro Moctezuma, etc.

El dibujo de la planta del cerro de Xochicalco que aparece en la lám. XXXII de la edición de Baradère, es copia casi idéntica del publicado por Alzate. La única diferencia es que en la edición francesa está equivocada la entrada a los subterráneos. Lo mismo puede decirse de la planta de éstos. Ambas versiones coinciden en la localización del tiro de ventilación y en la colocación de los pilares de piedra que, en la realidad, no son las correctas; además, se adoptan las mismas convenciones para el dibujo y podría decirse que las dos ilustraciones son idénticas, excepto en pequeñas variantes en las dimensiones y nomenclatura, así como en la flecha de orientación que está invertida en el dibujo de Agüera.

Más aún sorprende el dibujo de la fachada de la pirámide de las Serpientes Emplumadas que aparece como lámina XXXI en la edición de Baradère (fig. 19). Es la misma fachada, la del Oriente, y coincide con el dibujo de Agüera en el punto de vista, en las proporciones de los cuerpos del edificio, y aún en los errores como son el extraño saliente que aparece en la parte superior del talud, la pequeña moldura debajo del friso y el quiebre en el extremo de la derecha de éste; todos estos detalles no existen en la realidad. Adicionalmente, recordemos que Alzate no interpretó correctamente la iconografía de los relieves y que, por lo tanto, el dibujo de Agüera está plagado de errores en la representación de éstos: los mismos errores se observan en la ilustración de la edición parisina. No se reconocen los cuerpos ondulantes de las serpientes emplumadas y sólo aparecen las cabezas de esos animales extraños que Humboldt interpretó como cocodrilos arrojando agua por las fauces. Dupaix tampoco interpretó esta iconografía correctamente pero se acercó más a la realidad al interpretar el cuerpo de las serpientes como "una especie de guirnalda,.. culebreando el plano... de sus tres lienzos". ${ }^{31}$ Sin embargo, en la lámina de la edición de Baradère no aparece indicio alguno de esta guirnalda, ni del cuerpo de la serpiente. La única diferencia entre las dós representaciones es que en

31 Ibid., pp. 64. 
la publicada por Baradère se aprecia parte del segundo cuerpo de la Pirámide, mismo que no aparece en ninguna de las otras versiones. Es probable que este cuerpo haya sido incorporado por el grabador $\mathrm{L}$. Vitasse, basándose en las descripciones del texto de Dupaix acerca de la existencia de dicho cuerpo. Adicionalmente, en el estado de la pirámide descrito por Alzate y por el mismo Dupaix, desde el punto de vista de esta ilustración no podrían verse los restos del segundo cuerpo.

Son tan parecidas las ilustraciones en la edición de París a las de Agüera, que Roberto Villaseñor dice que "las ilustraciones que Márquez agrega a la descripción de Xochicalco, se atribuyen a Dupaix" ${ }^{32}$ Esta atribución es imposible, pues Márquez publica su opúsculo en 1804 y Dupaix no llega a Xochicalco sino hasta 1805. Sabemos, además, que los dibujos publicados por Márquez fueron copiados de los de Agüera. Añade Villaseñor: "Debemos a Dupaix y Castañeda los primeros informes veraces de su existencia [de Xochicalco]". ${ }^{33}$ Tampoco se puede aceptar esta aseveración pues, como ya vimos, los informes de Alzate y los dibujos de Agüera son tanto o más veraces, más completos y anteceden por varios años a los de Dupaix y Castañeda.

Charles Farcy, en el "Discurso Preliminar" a la edición de Baradère, refiriéndose al dibujo de la Pirámide de Xochicalco, nos dice que el diseño de Castañeda sigue muy exactamente el antecedente del dibujo dado a conocer por Alzate y después repetido por el p. Márquez y por Humboldt. ${ }^{34}$ Por todas las semejanzas que he mencionado antes, inclusive la repetición de los mismos errores que aparecen en los grabados, se podría suponer que Castañeda no solamente se inspiró en, sino que inclusive copió servilmente todos los dibujos de Xochicalco que años antes había elaborado Agüera.

Por otra parte, al examinar la edición de los viajes de Dupaix publicada en 1831 por Lord Kingsborough, podemos apreciar que la ilustración de la Pirámide (fig. 15) también atribuida a Castañeda, difiere considerablemente de la publicada por Baradère. Las proporciones arquitectónicas de talud, friso y cornisa son menos exactas, pues muestra una cornisa exageradamente alta. Por el contrario, la iconografía en el grabado de la edición Kingsborough se aproxima más a la realidad y ya es posible reconocer el cuerpo ondulante de la serpiente,

\footnotetext{
32 Roberto Villaseñor en Dupaix, op cit., 1978, p. 23.

33 Ibid., p. 35.

34 Charles Farcy en Dupaix, op. cit., 1834, p. 48 .
} 
coincidiendo así con la interpretación de "guirnalda serpenteante" que le dio Dupaix. También se puede reconocer la cabeza de la serpiente por la lengua bífida que se enrolla en su extremo. Otros elementos de la iconografía, como son los personajes sentados a la oriental entre las ondulaciones del cuerpo serpentino, y varios de los glifos, están representados en forma más correcta y reconocible.

Ahora bien, al comparar las dos versiones publicadas en el siglo XIX, la de Kingsborough y la de Baradère, con el dibujo de la pirámide en el Manuscrito de Sevilla (fig. 18) es obvia la mayor correspondencia de éste con el grabado de la edición Kingsborough, a pesar de las modificaciones introducidas por el grabador Aglio. Esta correspondencia es más notoria en cuanto a las erróneas proporciones arquitectónicas del edificio y también en la más correcta interpretación de los relieves de la fachada. Los dibujos de Xochicalco en el Manuscrito de Sevilla son únicamente tres: la planta de los subterráneos, el corte del respiradero de estas salas y la fachada oriente de la Pirámide (figs. 17 y 18). Es significativo que estas tres vistas sean también las únicas que aparecen en la edición de Kingsborough que, como ya vimos, están basadas en copias de los dibujos de Castañeda obtenidas por Latour-Allard en México.

No me parece razonable que Castañeda tuviera que copiar las ilustraciones de otros dibujantes. Tampoco me parece lógico que teniendo Castañeda una mejor comprensión de los relieves en la fachada de la Pirámide -como lo demuestra en el dibujo del Manuscrito de Sevilla y en el grabado de la edición de Kingsborough- tuviera que presentar una versión menos exacta como aparece en la edición de Baradère.

Todo lo anterior me lleva a varias conclusiones:

1. Los dibujos de Xochicalco en el Manuscrito de Sevilla, o son originales de Castaneda, o buenas copias de los mismos.

2. Los grabados de la edición Kingsborough, por su similitud con los dibujos del Manuscrito de Sevilla en las proporciones arquitectónicas y en la interpretación de la inconografía de los relieves, fueron tomados de copias bastante fieles de los dibujos de Castaneda conseguidas en México por Latour-Allard.

3. Por el contrario, los grabados de la edición de Baradère están basados, no en dibujos de Castañeda, sino en grabados de Agüera, como originalmente los publicó Alzate en 1791, y que fueron reproducidos por Márquez en 1804.

El mismo Baradère nos dice: 
Este importante monumento de Xochicalco, siendo digno de toda la atención de los anticuarios y los arqueólogos... hemos buscado los escritos por Antonio Alzate en 1791 y por Pedro Márquez en 1804 ... El primero de estos escritos, impreso en México, en lengua española, ha escapado a nuestras búsquedas; parece cierto que no existe en ninguna de nuestras bibliotecas públicas. [Del] segundo, impreso en Roma... la Biblioteca Real... posee un ejemplar. ${ }^{35}$

Considero, por lo tanto, que aunque Isidro Ignacio Icaza, el conservador del Museo Nacional, certificó que eran originales de Castañeda los dibujos que entregó a Baradère, las ilustraciones de Xochicalco que aparecen en su edición no están tomadas de dibujos de Castañeda sino de los de Agüera como fueron reproducidos por el p. Márquez.

Una hipótesis plausible para explicar todas estas irregularidades, es que el dibujo de la fachada realizado por Castañeda, o no le fue entregado o se le extravió a Baradère, por lo que tuvo que recurrir a copiar el grabado del artículo del p. Márquez. También cabe la posibilidad, por supuesto, que Baradère haya preferido la versión de Agüera. Al mismo tiempo, y para mejor ilustrar a Xochicalco, aprovechó otros dos de los grabados de Agüera que aparecen en el opúsculo de Márquez: la vista general del sitio y la planta del Cerro Xochicalco. Estas dos figuras no habían sido dibujadas por Castañeda y, consecuentemente, no aparecen ni en la edición de Kingsborough ni en el Manuscrito de Sevilla. Solamente así me puedo explicar las irregularidades en las ilustraciones de Xochicalco que aparecen en las diversas ediciones de los viajes de Dupaix.

No ha sido mi intención menospreciar la obra de Dupaix y Castañeda, muy valiosa y ampliamente reconocida. Mi análisis se ha basado primordialmente en la parte de su obra que se refiere a Xochicalco y he querido dar crédito al p. Alzate, el verdadero primer cronista de este interesante y apasionante monumento prehispánico. También he intentado aclarar el misterio de las muy diferentes versiones de los dibujos de Xochicalco atribuidos a José Luciano Castañeda.

35 Jean-Henri Baradère en Dupaix, op. cit., 1834, p. 47. 